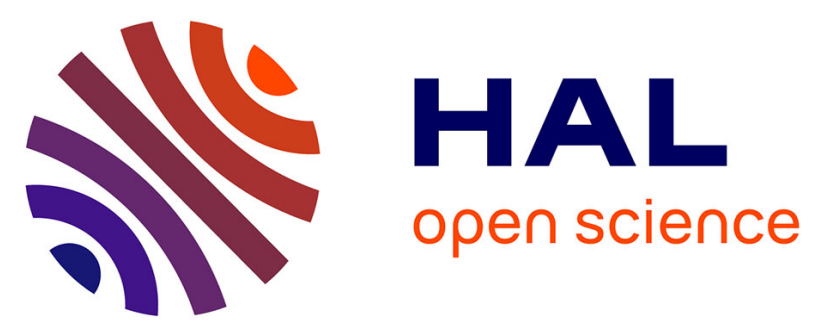

\title{
Conformationnally restricted naphthalene derivatives type isocombretastatin A-4 and isoerianin analogues: Synthesis, cytotoxicity and antitubulin activity
}

Evelia Rasolofonjatovo, Olivier Provot, Abdallah Hamze, Jordi Rodrigo, Jérôme Bignon, Joanna Wdzieczak-Bakala, Déborah Desravines, Joëlle Dubois, Jean-Daniel Brion, Mouad Alami

\section{To cite this version:}

Evelia Rasolofonjatovo, Olivier Provot, Abdallah Hamze, Jordi Rodrigo, Jérôme Bignon, et al.. Conformationnally restricted naphthalene derivatives type isocombretastatin A-4 and isoerianin analogues: Synthesis, cytotoxicity and antitubulin activity. European Journal of Medicinal Chemistry, 2012, 52, pp.22-32. 10.1016/j.ejmech.2012.03.001 . hal-02394400

\author{
HAL Id: hal-02394400 \\ https://hal.science/hal-02394400
}

Submitted on 4 Dec 2019

HAL is a multi-disciplinary open access archive for the deposit and dissemination of scientific research documents, whether they are published or not. The documents may come from teaching and research institutions in France or abroad, or from public or private research centers.
L'archive ouverte pluridisciplinaire HAL, est destinée au dépôt et à la diffusion de documents scientifiques de niveau recherche, publiés ou non, émanant des établissements d'enseignement et de recherche français ou étrangers, des laboratoires publics ou privés. 


\title{
Conformationnally restricted naphthalene derivatives type isocombretastatin A-4 and isoerianin analogues: Synthesis, cytotoxicity and antitubulin activity
}

\author{
Evelia Rasolofonjatovo, ${ }^{\mathrm{a}}$ Olivier Provot, ${ }^{* a}$ Abdallah Hamze, ${ }^{\mathrm{a}}$ Jordi Rodrigo, ${ }^{\text {a }}$ Jérome \\ Bignon, ${ }^{b}$ Joanna Wdzieczak-Bakala, ${ }^{\mathrm{b}}$ Déborah Desravines, ${ }^{\mathrm{b}}$ Joëlle Dubois, ${ }^{\mathrm{b}}$ Jean-Daniel \\ Brion, ${ }^{a}$ Mouad Alami*a \\ ${ }^{a}$ Univ. Paris-Sud, CNRS, BioCIS-UMR 8076, LabEx LERMIT, Laboratoire de Chimie Thérapeutique, Faculté de Pharmacie, 5 rue \\ J.-B. Clément, Châtenay-Malabry, F-92296, France. \\ ${ }^{b}$ Institut de Chimie des Substances Naturelles, UPR 2301, CNRS avenue de la terrasse, F-91198 Gif sur Yvette, France. \\ * Corresponding authors. Tel.: +3314468358 47. Fax: +33 1468358 28. Email: olivier.provot@u-psud.fr (O.P.) or \\ mouad.alami@u-psud.fr (M.A.).
}

\begin{abstract}
A novel series of dihydronaphtalene, tetrahydronaphtalene and naphtalene derivatives as restricted-analogues of $i s o \mathrm{CA}$ 4 were designed, synthesized and evaluated for their anticancer properties. High cell growth inhibition against four tumor cell lines was observed at a nanomolar level with dihydronaphtalenes $\mathbf{1 d}, \mathbf{e}$ and $\mathbf{1 h}$, tetrahydronaphtalene $\mathbf{2 c}$ and naphtalene 3c. Structure activity relationships are also considered. These compounds exhibited a significant inhibitory activity toward tubulin polymerization $\left(\mathrm{IC}_{50}=2-3 \mu \mathrm{M}\right)$, comparable to that of isoCA-4. The effect of the lead compounds $1 \mathbf{e}$ and $\mathbf{2 c}$ on the cancer cells tested was associated with cell cycle arrest in the $\mathrm{G}_{2} / \mathrm{M}$ phase. Docking studies reveal that these compounds showed a binding mode similar to those observed with their non-constraint isoCA-4 and isoerianin congeners.
\end{abstract}

Keywords: Combretastatin A-4, isoCA-4, Cytotoxicity, Antimitotic, Tubulin, Restricted analogues 


\section{Introduction}

Microtubules found in cytoskeleton of almost all eukaryotic cell types are hollow tubes formed by self-assembly of $\alpha$ and $\beta$ tubulin heterodimers. They are directly involved in a variety of cellular functions, such as cell movement, transport of organelles inside the cell, maintenance of cell shape as well as mitosis and cell replication. Consequently, perturbation of tubulin assembly/disassembly is a popular target for new chemotherapeutic agents.[1,2] The vinca alkaloids, typified by vinblastine and vincristine which inhibit microtubules assembly[3] as well as the taxanes, such as paclitaxel and docetaxel which promoted microtubules polymerization and inhibits microtubules depolymerization,[4,5] are the mostly used antimicrotubules agents introduced in clinical oncology.[6] However, despite their potent antitumor activities, these drugs have undesirable side effects[7,8] and are subject to multidrug resistance.[9,10] These last decades, there has been a strong enthusiasm for discovering tubulin polymerization inhibitors of small size, easy synthesis and low side effects. Combretastatin A-4 (CA-4, Figure 1), a cis-stilbene extracted from the South African willow Combretum caffrum[11,12] is arguably the most studied substance that displays a nanomolar level of cytotoxicity against a variety of human cancer cells, including multidrug resistant cell lines.[13,14] CA-4 binds at or near colchicine binding site of $\beta$-tubulin and strongly interferes with the assembly of tubulin, leading to cell death.[15] It also exerts highly selective effects in proliferating endothelial cells and, as a consequence, demonstrates strong suppressive activity on tumor blood flow leading to tumor necrosis.[16] Two derivatives are currently in clinical trials: CA-4 disodium phosphate CA-4P, $[17,18]$ a water soluble prodrug of CA-4 and the aminocombretastatin prodrug AVE8062 (3).[19,20] To date, CA-4P[21] either as a single agent or in combination therapy is undergoing several advanced clinical trials worldwide for the treatment of age-related macular degeneration or anaplastic thyroid cancer.

Despite its remarkable anticancer activity, the main disadvantage of CA-4 is the ready isomerization of the Z-double bond to its inactive trans-form during storage, administration[22] and metabolism.[23] In an ongoing project aimed at developing novel tubulin assembly inhibitors,[24,25,26,27,28,29] we recently discovered isocombretastatin A-4 (isoCA-4), a structural isomer of the natural product, which holds biological activities comparable to that of CA-4.[30] This substance having a 1,1-diarylethylene scaffold is easy to synthesize[31,32,33] at a multi grams scale without the need to control the olefin geometry and then definitively solving the $Z$ double bond isomerization problem.[34]

\section{<Figure 1>}

By structural modifications on the B-ring, we have also identified other promising antiproliferative agents such as iso $\mathrm{NH}_{2} \mathrm{CA}-4$ and isoFCA-4 (Figure 1).[35,36] We also demonstrated that the bioisosteric replacement of the $(Z)-1,2-$ ethylene by the 1,1-ethylene could be apply successfully to natural combretastatins CA-2, CA-3 and CA-5.[30] On the basis of these bioisosteric considerations, we also showed that isoerianin derivatives having a 1,1-diarylethane scaffold were as active as the natural product erianin.[37] A set of molecular docking calculations was performed with isoCA-4 as well as isoerianin which showed a binding pose similar to those observed with CA-4 and the co-crystallized DAMAcolchicine in the colchicine binding site.[38] In addition, the dihedral angles between the planes of the two A/Baromatic nucleus in isoCA-4 and isoerianin ( $68^{\circ}$ and $77^{\circ}$, respectively)[30,37] were found to be close to that of CA-4 $\left(53^{\circ}\right)$.[39] From all of these considerations, we are planning to rationalize the synthesis of three new series of rigid analogues of isoCA-4 and isoerianin namely, 4-aryldihydronaphtalenes $\mathbf{1}$ (e.g.; dihedral angle $=69^{\circ}$ for $1 \mathbf{e}$ ), 4 aryltetrahydronaphtalenes 2 (e.g.; dihedral angle $=79^{\circ}$ for $\mathbf{2 c}$ ) and 1-arylnaphtalenes 3 (e.g.; dihedral angle $=70^{\circ}$ for 3d) with reduced mobility of the B-ring. We hypothesized that constrained analogues $\mathbf{1 - 3}$ with dihedral angles close to those of isoCA-4 and isoerianin would be as active as their non restricted congeners. In this paper we would like to describe the synthesis and evaluation of compounds 1-3 in terms of inhibition of tubulin assembly along with cytotoxicity studies against various cancer cell lines. 
Reagents and conditions: (i) $p \mathrm{TsNHNH}_{2}$ (1.2 equiv), PTSA (0.2 equiv), $\mathrm{MgSO}_{4}$ ( 1 equiv), EtOH, $50{ }^{\circ} \mathrm{C}$. (ii) $\mathrm{ArI}$ (1.1 equiv), $\mathrm{Pd}_{2} \mathrm{dba}_{3}\left(10 \mathrm{~mol} \%\right.$ ), XPhos (20 mol\%), LiOtBu (2.2 equiv), dioxane $90{ }^{\circ} \mathrm{C}$ in a sealed tube. (iii) 3,4,5trimethoxyiodobenzene (1.1 equiv), $\mathrm{Pd}_{2} \mathrm{dba}_{3}(10 \mathrm{~mol} \%)$, XPhos $(20 \mathrm{~mol} \%), \mathrm{LiO} t \mathrm{Bu}\left(2.2\right.$ equiv), dioxane $90{ }^{\circ} \mathrm{C}$ in a sealed tube. (iv) $\mathrm{NaN}_{3}$ (2 equiv), CuI 10 mol\%, DMEDA (15 mol\%), sodium ascorbate (5 mol\%), DMSO/ $\mathrm{H}_{2} \mathrm{O}: 5 / 1,60$ ${ }^{\circ} \mathrm{C}$. (v) $\mathrm{KOH}$ (5 equiv), $\mathrm{Pd}_{2} \mathrm{dba}_{3}(10 \mathrm{~mol} \%)$, $t$ BuXPhos $(20 \mathrm{~mol} \%)$, dioxane $/ \mathrm{H}_{2} \mathrm{O}: 1 / 1,90{ }^{\circ} \mathrm{C}$ in a sealed tube. (vi) Alkyne (1.2 equiv), $\mathrm{PdCl}_{2}\left(\mathrm{PPh}_{3}\right)_{2}$ (5 mol\%), $\mathrm{PPh}_{3}$ (10 mol\%), CuI (10 mol\%), $\mathrm{Et}_{2} \mathrm{NH}$ (2 equiv), DMF, MWI, $120{ }^{\circ} \mathrm{C}$. (vii) Methyl acrylate (10 equiv), PEPPSI (5 mol\%), $\mathrm{K}_{2} \mathrm{CO}_{3}$ (2 equiv), NMP $140{ }^{\circ} \mathrm{C}$ in a sealed tube. (viii) $\mathrm{H}_{2}, \mathrm{Pd} / \mathrm{C}$ in MeOH. (ix) DDQ (1.2 equiv), $\mathrm{CH}_{2} \mathrm{Cl}_{2}, 20^{\circ} \mathrm{C}$.

\section{Results and discussion}

\subsection{Chemistry.}

Scheme 1 outlines the convergent synthetic routes followed for the synthesis of the novel restricted analogues 1-3. The projected incorporation of a variety of substituents at the $\mathrm{C} 3$ ' position of the B-ring trusts in the tractability of a $\mathrm{C} \square \mathrm{Br}$ bond, which can further be engaged into diverse coupling reactions. Thus, the preparation of the pivotal brominated precursors 1a and $\mathbf{1 b}$ was achieved from 5-bromo-6-methoxytetralone $4 \mathbf{b}$ [40] which was heated in $\mathrm{EtOH}$ at $50{ }^{\circ} \mathrm{C}$ with $\mathrm{TsNHNH}_{2}$ in the presence of PTSA. The resulting $N$-tosylhydrazone $\mathbf{5} \mathbf{b}$ was next coupled with aryl iodides under palladium catalysis[30,41,42] to afford the key intermediates 1a,b. By securing the required skeleton for the dihydronaphtalene analogues, the stage was ready for the installation of various functionalities in place of the bromine atom. The $\mathrm{C}\left(\mathrm{sp}^{2}\right) \square \mathrm{NH}_{2}$ bond of $\mathbf{1 d}$ and $\mathbf{1 i}$ was formed from $\mathbf{1 a}$ and $\mathbf{1 b}$, respectively, using sodium azide as the amino source[43,44] in the presence of a catalytic amount of CuI. Treating $1 \mathbf{a}, \mathbf{b}$ with $\mathrm{KOH}$ in the presence of $\mathrm{Pd}_{2} \mathrm{dba}_{3}$, $t$ BuXPhos in a mixture dioxane $/ \mathrm{H}_{2} \mathrm{O}: 1 / 1$ at $90{ }^{\circ} \mathrm{C}[45]$ delivered in good yields the $\mathrm{C} 3$ '-hydroxy substituted analogues 1e $(63 \%)$ and $\mathbf{1 h}(62 \%)$. For the introduction of alkyne substituents on the B-aromatic ring,[36] we examined the Sonogashira-Linstrumelle reaction[46] of 1a with propargylic and homopropargylic alcohols. The coupling reaction of these alcohols with 1a proceeded in the presence of $\mathrm{PdCl}_{2}\left(\mathrm{PPh}_{3}\right)_{2}$ and $\mathrm{CuI}$ catalysts under microwave irradiation (MWI) at $120{ }^{\circ} \mathrm{C}$ to give the corresponding alkynes 1f,g in good yields. Similarly, 1a underwent Heck coupling with methyl acrylate using [1,3-bis(2,6-diisopropylphenyl)imidazol-2-ylidene](3-chloropyridyl)palladium(II) dichloride (PEPPSI) as the catalyst in NMP at $140{ }^{\circ} \mathrm{C}$ to afford the corresponding 3 'methyl $(E)$-cinnamate $\mathbf{1 j}$ in an unoptimized $35 \%$ yield.

Having achieved the preparation of dihydronaphtalenes 1, we next focused our attention on their catalytic reduction to give restricted isoerianin analogues 2. Thus, 4-aryltetrahydronaphtalenes 2a-e were obtained in acceptable yields using $\mathrm{H}_{2}$ in the presence of $\mathrm{Pd} / \mathrm{C}$ in $\mathrm{MeOH}$. Finally, aromatization of compound 1a into naphtalene derivative 3a was attempted using a variety of oxidizing species, including $\mathrm{Pd} / \mathrm{C}, \mathrm{SeO}_{2}, o$-chloranil, $p$-chloranil, and $\mathrm{SO}_{3}$-pyridine complex. However, the oxidation reactions were unsuccessful and gave 3a in very poor yields $(<10 \%)$. After several trials, we found that the oxidation of $\mathbf{1 a}$ with DDQ in $\mathrm{CH}_{2} \mathrm{Cl}_{2}$ afforded the desired naphtalene 3a but in a moderate $33 \%$ yield. Introduction of various substituents on 3a was next achieved in a similar manner as described above for 1d-j from 1a,b. Using a similar route for the synthesis of $\mathbf{1 d}$, dihydronaphtalene $\mathbf{1 l}$ bearing a $\mathrm{NH}_{2}$ substituent at the C-7 position was prepared from 7-bromo-6-methoxytetralone 4c[47] for structure-activity relation study (Scheme 2).

\section{<Scheme 2>}

Reagents and conditions: (i) $p \mathrm{TsNHNH}_{2}$ (1.2 equiv), PTSA (0.2 equiv), $\mathrm{MgSO}_{4}$ ( 1 equiv), EtOH, $50{ }^{\circ} \mathrm{C}$. (ii) $3,4,5-$ trimethoxyiodobenzene (1.1 equiv), $\mathrm{Pd}_{2} \mathrm{dba}_{3}(10 \mathrm{~mol} \%)$, XPhos $(20 \mathrm{~mol} \%), \mathrm{LiO} t \mathrm{Bu}(2.2 \mathrm{equiv})$, dioxane $90{ }^{\circ} \mathrm{C}$ in a sealed tube. (iii) $\mathrm{NaN}_{3}$ (2 equiv), $\mathrm{CuI}\left(10 \mathrm{~mol} \%\right.$ ), DMEDA (15 mol\%), sodium ascorbate (5 mol\%), DMSO/ $\mathrm{H}_{2} \mathrm{O}: 5 / 1$, $60{ }^{\circ} \mathrm{C}$. 


\subsection{Biological results.}

In vitro antiproliferative activity of the synthesized naphthalene derivatives 1-3 was first determined against the human colon carcinoma cell line (HCT116) using CA-4[48] and isoCA-4[30] and isoerianin[37] as reference compounds. The results of this study are summarized in Table 1 . On the exception of the amino derivative $\mathbf{3 c}\left(\mathrm{GI}_{50}=55 \mathrm{nM}\right)$, naphtalene compounds $\mathbf{3}$ displayed only modest antiproliferative activity, which was affected with halogen (Br, 3a), alkynol (3e, 3f), alkene (3g) and alkyl (3h) substituents at the C5 position. In contrast, dihydronaphtalenes $\mathbf{1}$ were significantly more active than their aromatic congeners. In particular, dihydronaphtalenes 1d and 1e[49] bearing the greatest resemblance to $i s o \mathrm{NH}_{2} \mathrm{CA}-4$ and isoCA-4, respectively, displayed a high antiproliferative activity at a nanomolar level $\left(\mathrm{GI}_{50}=7\right.$ and $85 \mathrm{nM}$ ). By comparison with 1d, the introduction of an amino substituent at the $\mathrm{C} 7$ position failed to improve the cytotoxic activity profile of $\mathbf{1 l}$. One note that compounds $\mathbf{1 h}$ and $\mathbf{1 i}$ bearing two methoxy groups on the A-ring retained an important cytotoxicity in comparison with 1e and 1d, respectively. Nevertheless, on the contrary with previous reports,[36] decreased cytotoxic activity was observed with dihydronaphtalenes $\mathbf{1 f}, \mathbf{g}$ and $\mathbf{1 j}$ bearing alkynol or alkene substituents at the $\mathrm{C} 5$ position.

The reduction of $\mathbf{1}$ into tetrahydronaphtalenes $\mathbf{2}$ as restricted isoerianin analogues led to compounds that displayed similar cytotoxic activities in comparison with isoerianin $\left(\mathrm{GI}_{50}=28 \mathrm{nM}\right)$ and with their dihydronaphtalenes precursors. For example, $2 \mathrm{c}$ with a $\mathrm{GI}_{50}$ value of $20 \mathrm{nM}$ was slightly more active than restricted isoCA-4 1e (85 nM), while the amino derivative $\mathbf{2 b}$ was about ten fold less active than its dihydronaphtalene analogue $\mathbf{1 d}$. These results indicated that rigidifying isoCA-4 or isoerianin with the dihydro- or tetrahydronaphtalene system did not alter the reported SAR. These preliminary in vitro cytotoxic results prompted us to evaluate the most promising molecules in these series against other human cancer cell lines. The $\mathrm{GI}_{50}$ values of selected compounds obtained with K562 (chronic mylogenous leukemia), H1299 (non-small lung human carcinoma) and MDA-MB231 (human breast) cell lines are summarized in Table 2.

\section{<Table 2>}

Results from the cytotoxicity study provide evidence that dihydronaphtalenes $\mathbf{1 d}, \mathbf{1 e}, \mathbf{1 h}, \mathbf{1 i}$ which retained a high level of cytotoxicity against HCT116 (Table 1) cells were also strongly cytotoxic against H1299, MDA-MB231 and K562 cancer cell lines. Similarly, tetrahydronaphtalenes $\mathbf{2 a - c}$ as well as naphtalene derivative $\mathbf{3 c}$ displayed an equivalent level of cytotoxicity against the three tested cancer cells $\left(30<\mathrm{GI}_{50}<150 \mathrm{nM}\right)$.

To confirm that the antiproliferative activities of these compounds, like those in the isoCA-4[30] and isoerianin series,[37] were related to an interaction with the microtubule system, these selected compounds were evaluated for their inhibitory effects on tubulin assembly (Table 2). Except for dihydronaphtalenes 2a and 2b, the results demonstrated that the drug cytotoxicity correlated with the inhibition of tubulin polymerization. For instance, dihydronaphatalenes $\mathbf{1 d}, \mathbf{e}, \mathbf{1 h}, \mathbf{i}$, tetrahydronaphtalene $\mathbf{2 c}$ and naphtalene $\mathbf{3 c}$ were found to be as active as isoCA-4 and CA-4, displaying an $\mathrm{IC}_{50}$ at a micromolar level. One note that naphtol derivative 3d, bearing the greatest ressemblance to isoCA-4, showed a reduced antitubulin activity $\left(\mathrm{IC}_{50}=6.9 \mu \mathrm{M}\right)$ which was consistent with the results of the growth inhibitory effect $\left(310 \mathrm{nM}<\mathrm{GI}_{50}<500 \mathrm{nM}\right)$.

Because molecules exhibiting effects on tubulin polymerization causes the alteration of cell cycle parameters, the effect of tetrahydronaphtalene 2c, dihydronaphtalene 1e, and naphtalene 3d on MDA-MB231, K562, HCT116 and H1299 cellular cycle was investigated. The fluorescent propidium iodide intercalates with the DNA and hence, the amount of fluorescence measured per cell is proportional to the DNA content. Cells were harvested after $24 \mathrm{~h}$ and analyzed for DNA content by flow cytometry. Table 3 shows that a significant increased in $G_{2} / M$ peak is observed after treatment of the four cell lines with tetrahydronaphtalene $2 \mathrm{c}$ at a low concentration $\left(5.10^{-9} \mathrm{M}\right)$. Similarly, dihydronaphtalene 1 e as 
well as naphtalene derivative $\mathbf{3 d}$ arrest the majority of cells in the $G_{2} / M$ phase of the cell cycle but at concentrations smootly superiors $\left(10^{-8} \mathrm{M}\right.$ and $5 \cdot 10^{-7} \mathrm{M}$, respectively).

\section{$<$ Table 3>}

\subsection{Docking study.}

These results clearly demonstrated that tubulin is the target of these compounds; however, the specific binding site on tubulin was not investigated, for example, by use of a radiolabeled colchicine displacement assay. Nevertheless, a set molecular docking calculations was performed with 5-OH naphtalene derivatives to investigate the possible binding mode of 2c, 1e and 3d which were docked in the colchicine binding site of tubulin. For this purpose, the X-ray structure of tubulin DAMA-colchicine complex (Code PDB: 1sa0)[38] was used. Figure 2 illustrates from one hand, the dockingderived superimposition of $\mathbf{2 c}$ and 1e, with isoCA-4 (blue), and on the other hand, the superimposition of $\mathbf{3 d}$ with isoerianin (green). As expected, these compounds showed a binding pose similar to the one observed with the reference compounds isoCA-4 and isoerianin with the trimethoxyphenyl ring placed in proximity of Cys 241 and the $\mathrm{OH}$ substituent of the B-ring (naphtalene, dihydro- and tetrahydronaphtalene) which forms a hydrogen-bond with Val181. These binding parallels and the dihedral angles values of $2 \mathbf{c}\left(79^{\circ}\right), \mathbf{1 e}\left(69^{\circ}\right)$ and $\mathbf{3 d}\left(70^{\circ}\right)$ probably rationalise the potency observed for these drugs in their tubulin effects which are seen to be close to that reported for isoCA-4 $\left(\right.$ dihedral angle $\left.=68^{\circ}\right)[30]$ and isoerianin $\left(\right.$ dihedral angle $\left.=77^{\circ}\right)$.[37]

\section{<Figure 2>}

\section{Conclusion}

We designed and synthesized by a convergent strategy, three new classes of synthetic inhibitors of tubulin polymerization based on the molecular skeleton of dihydronaphtalenes $\mathbf{1}$, tetrahydronaphtalenes $\mathbf{2}$ and naphtalenes $\mathbf{3}$. These restricted analogues of isoCA-4 and isoerianin were evaluated for their antiproliferative activity against various human cancer cell lines. The lead compounds, dihydronaphtalenes $\mathbf{1 e - h}$, tetrahydronaphtalenes $\mathbf{2 b}, \mathbf{c}$ and to a lesser extent naphtalene $3 \mathbf{c}$ displayed potent cytotoxicities with $\mathrm{GI}_{50}$ ranging from 15 to $110 \mathrm{nM}$. In these three series, six of the most cytotoxic compounds were evaluated for effects on tubulin polymerization and the $\mathrm{IC}_{50}$ values in a nearly range of $3 \mu \mathrm{M}$ are comparable to that of isoCA-4. The three most potent inhibitors of tubulin assembly having the

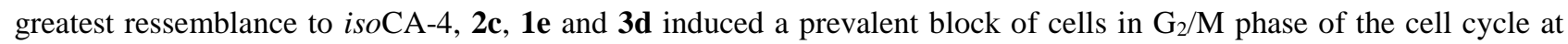
nanomolar concentrations. In addition, docking studies revealed that these compounds adopted an orientation similar to that of isoCA-4 and isoerianin in the colchicine binding-site. Biological results obtained in this study demonstrate that structural restrictions at this portion of isoCA-4 offers various permises for the design of novel heterocycle-containing restricted isoCA-4 derivatives. Synthesis and biological evaluation of such compounds are under investigation in our laboratory and will be reported in due course.

\section{Experimental}

\subsection{General considerations}

Triethylamine was distilled from potassium hydroxide under argon prior to use. The compounds were all identified by usual physical methods, i.e. ${ }^{1} \mathrm{H}-\mathrm{NMR},{ }^{13} \mathrm{C}-\mathrm{NMR}$, IR, MS and elemental analysis. ${ }^{1} \mathrm{H}$ and ${ }^{13} \mathrm{C}$ NMR spectra were measured in $\mathrm{CDCl}_{3}$ with a Bruker Avance 300. ${ }^{1} \mathrm{H}$ chemical shifts are reported in ppm from an internal standard TMS or of residual chloroform (7.27 ppm). The following abbreviations are used: m (multiplet), s (singlet), d (doublet), br s (broad singlet), $\mathrm{t}$ (triplet). ${ }^{13} \mathrm{C}$ chemical shifts are reported in ppm from the central peak of $\mathrm{CDCl}_{3}$ (77.14). IR spectra were measured on a Bruker Vector 22 spectrophotometer (neat, $\mathrm{cm}^{-1}$ ). Elemental analyses were performed with a Perkin-Elmer 240 analyser. Mass spectra were obtained with a LCT Micromass spectrometer. Analytical TLC was 
performed on Merck precoated silica gel 60F plates. Merck silica gel 60 (230-400 mesh) was used for column chromatography.

\subsection{Bromination of 6-methoxytetralone was achieved according to literature to give $\mathbf{4 b}$ and $\mathbf{4 c}$.[40]}

\subsubsection{5-Bromo-6-methoxytetralone $(\mathbf{4 b})$}

Yield: $49 \%$. TLC: Rf 0.52 (cyclohexane/EtOAc: 9/1). IR (neat) $v_{\max } / \mathrm{cm}^{-1}:$ 3904, 3232, 1664, 1568, 1458, 1415, 1352, 1327, 1280, 1232, 1188, 904, 826, 776, 729, 638. ${ }^{1} \mathrm{H}$ NMR $\left(300 \mathrm{MHz}, \mathrm{CDCl}_{3}\right) \delta \mathrm{ppm} 8.06(\mathrm{~d}, J=8.7 \mathrm{~Hz}, 1 \mathrm{H}), 6.88(\mathrm{~d}$, $J=8.7 \mathrm{~Hz}, 1 \mathrm{H}), 3.97(\mathrm{~s}, 3 \mathrm{H}), 3.03(\mathrm{t}, J=6.2 \mathrm{~Hz}, 2 \mathrm{H}), 2.66-2.54(\mathrm{~m}, 2 \mathrm{H}), 2.14(\mathrm{~m}, 2 \mathrm{H}) .{ }^{13} \mathrm{C} \mathrm{NMR}\left(75 \mathrm{MHz}, \mathrm{CDCl}_{3}\right) \delta$ 196.9, 159.8, 145.6, 128.5, 127.7, 113.1, 109.7, 56.6, 38.1, 30.6, 22.6. MS (APCI, m/z) $255.1\left([\mathrm{M}+\mathrm{H}]^{+},{ }^{79} \mathrm{Br}\right), 257.0$ $\left([\mathrm{M}+\mathrm{H}]^{+},{ }^{81} \mathrm{Br}\right)$.

4.2.2 7-Bromo-6-methoxytetralone (4c)

Yield: 7 \%. Rf 0.45 (cyclohexane/ EtOAc: 9/1). IR (neat) $v_{\max } / \mathrm{cm}^{-1}: 3628,3238,1668,1568,1459,1413,1352,1327$, 1283, 1260, 1232, 1188, 902, 778, 733, 640. ${ }^{1} \mathrm{H}$ NMR (300 MHz, $\left.\mathrm{CDCl}_{3}\right) \delta \mathrm{ppm} 8.21(\mathrm{~s}, 1 \mathrm{H}), 6.69(\mathrm{~s}, 1 \mathrm{H}), 3.94(\mathrm{~s}, 3 \mathrm{H})$, $2.91(\mathrm{t}, J=6.0 \mathrm{~Hz}, 2 \mathrm{H}), 2.75-2.41(\mathrm{~m}, 2 \mathrm{H}), 2.12(\mathrm{~m}, 2 \mathrm{H}) .{ }^{13} \mathrm{C} \mathrm{NMR}\left(75 \mathrm{MHz}, \mathrm{CDCl}_{3}\right) \delta 196.0,159.6,159.4,151.4$, 145.9, 132.6, 110.8, 56.4, 38.5, 29.9, 23.2. MS (APCI, m/z) 255.0 ([M + H $\left.]^{+},{ }^{79} \mathrm{Br}\right), 257.0\left([\mathrm{M}+\mathrm{H}]^{+},{ }^{81} \mathrm{Br}\right)$.

4.3. General procedure for the formation of $N$-tosylhydrazones.

To a solution of tetralone $\mathbf{4 b , c}(1 \mathrm{mmol})$, PTSA $(0.2 \mathrm{mmol})$ and $\mathrm{MgSO}_{4}(1 \mathrm{mmol})$ in ethanol $(20 \mathrm{~mL})$ was added 4 methylbenzenesulfonohydrazide $(1.2 \mathrm{mmol})$. The resulting mixture was stirred under reflux for $2 \mathrm{~h}$. After cooling at room temperature, the medium was diluted with EtOAc and filtered over a pad of Celite. The solvent was next removed and the residue was purified by crystallization in ethanol to afford $\mathbf{5 b , c}$.

4.3.1. N'-(5-Bromo-6-methoxy-3.4-dihydronaphtalen-1(2H)-ylidene)-4-methylbenzenesulfonohydrazide (5b)

Yield: $100 \%$. M.p. $212.1^{\circ} \mathrm{C}$ Rf 0.5 (cyclohexane/EtOAc: 7/3). IR (neat) $v_{\max } / \mathrm{cm}^{-1}: 2249,1054,1025,1006,821,758$, 623. ${ }^{1} \mathrm{H}$ NMR $(300 \mathrm{MHz}, \mathrm{DMSO}) \delta \mathrm{ppm} 10.51-10.03$ (br s, 1H), $7.85-7.73(\mathrm{~m}, 3 \mathrm{H}), 7.40(\mathrm{~d}, J=8.1 \mathrm{~Hz}, 2 \mathrm{H}), 7.01(\mathrm{~d}$, $J=8.9 \mathrm{~Hz}, 1 \mathrm{H}), 3.85(\mathrm{~s}, 3 \mathrm{H}), 2.75(\mathrm{t}, J=6.0 \mathrm{~Hz}, 2 \mathrm{H}), 2.52-2.47(\mathrm{~m}, 2 \mathrm{H}), 2.37(\mathrm{~s}, 3 \mathrm{H}), 1.77(\mathrm{~m}, 2 \mathrm{H}) .{ }^{13} \mathrm{C} \mathrm{NMR}(75$ MHz, DMSO) $\delta 156.21,152.15,143.14,140.06,136.50,129.39$ (2C), 127.61 (2C), 126.37, 124.76, 112.31, 110.58, $56.39,29.29,25.12,21.03,20.86$.

4.3.2. N'-(7-Bromo-6-methoxy-3.4-dihydronaphtalen-1(2H)-ylidene)-4-methylbenzenesulfonohydrazide (5c)

Yield: 98 \%. M.p. $236^{\circ} \mathrm{C}$ Rf 0.5 (cyclohexane/ EtOAc: 7/3). IR (neat) $v_{\max } / \mathrm{cm}^{-1}: 2249,1054,1025,1016,992,821$, 701, 654. ${ }^{1} \mathrm{H}$ NMR (300 MHz, DMSO) $\delta$ ppm 10.39 (br s, 1H), $7.92-7.70$ (m, 3H), 7.42 (d, J = 7.8 Hz, 2H), $6.91(\mathrm{~s}$, 1H), $3.84(\mathrm{~s}, 3 \mathrm{H}), 3.35-3.30(\mathrm{~m}, 2 \mathrm{H}), 2.76-2.59(\mathrm{~m}, 2 \mathrm{H}), 2.38(\mathrm{~s}, 3 \mathrm{H}), 1.85-1.65(\mathrm{~m}, 2 \mathrm{H}) .{ }^{13} \mathrm{C} \mathrm{NMR}(75 \mathrm{MHz}$, DMSO) $\delta 156.3,152.1,143.8,141.8,136.7,129.9$ (2C), 128.8, 127.9 (2C), 126.0, 112.5, 109.3, 56.8, 29.1, 25.9, 21.5, 21.4 .

4.4. General procedure for the coupling of $N$-tosylhydrazones with aryl iodides.

To a dioxane $(2 \mathrm{~mL})$ solution of $N$-tosylhydrazone (0.24 mmol), $t \mathrm{BuOLi}(0.53 \mathrm{mmol}), \mathrm{Pd}_{2} \mathrm{dba}_{3}(0.02 \mathrm{mmol})$, and XPhos $(0.04 \mathrm{mmol})$ was added the required aryl iodide $(0.24 \mathrm{mmol})$. The mixture was stirred at $90{ }^{\circ} \mathrm{C}$ for $5 \mathrm{~h} . \mathrm{CH}_{2} \mathrm{Cl}_{2}(5 \mathrm{~mL})$ was then added to the cooled mixture which was filtered over a pad of Celite. After concentration, the residue was purified by silica gel chromatography to yield $\mathbf{1 a - c , ~} \mathbf{1 k}$.

4.4.1. 8-Bromo-7-methoxy-4-(3,4,5-trimethoxyphenyl)-1,2-dihydronaphtalene (1a)

Yield: $76 \%$. Rf 0.4 (cyclohexane/EtOAc: 7/3). IR (neat) $v_{\max } / \mathrm{cm}^{-1}:$ 2931, 1591, 1421, 1331, 1267, 1204, 1154, 1062, 994, 906, 857, 729, 648. ${ }^{1} \mathrm{H}$ NMR $\left(300 \mathrm{MHz}, \mathrm{CDCl}_{3}\right) \delta 6.90(\mathrm{~d}, J=8.5 \mathrm{~Hz}, 1 \mathrm{H}), 6.60(\mathrm{~d}, J=8.5 \mathrm{~Hz}, 1 \mathrm{H}), 6.45(\mathrm{~s}, 2 \mathrm{H})$, $5.91(\mathrm{t}, J=4.6 \mathrm{~Hz}, 1 \mathrm{H}), 3.81(\mathrm{~s}, 6 \mathrm{H}), 3.77(\mathrm{~s}, 6 \mathrm{H}), 2.96(\mathrm{t}, J=7.9 \mathrm{~Hz}, 2 \mathrm{H}), 2.33(\mathrm{dt}, J=4.8 \mathrm{~Hz}, J=7.9 \mathrm{~Hz}, 2 \mathrm{H}) .{ }^{13} \mathrm{C}$ NMR (75 MHz, $\left.\mathrm{CDCl}_{3}\right) \delta 154.9,153.0$ (2C), 139.2, 138.2, 137.3, 136.4, 129.8, 125.4, 125.4, 113.6, $108.8,105.9$ (2C), 60.9, 56.3, 56.1 (2C), 28.1, 23.0. MS (APCI, m/z) $405.7\left([\mathrm{M}+\mathrm{H}]^{+},{ }^{79} \mathrm{Br}\right), 407.2\left([\mathrm{M}+\mathrm{H}]^{+},{ }^{81} \mathrm{Br}\right)$. Anal. Calcd for $\mathrm{C}_{20} \mathrm{H}_{21} \mathrm{BrO}_{4}$ : C 59.27, H 5.22, found C 59.10, H 5.09. 
4.4.2. 8-Bromo-4-(3,5-dimethoxyphenyl)-7-methoxy-1,2-dihydronaphtalene (1b)

Yield: $84 \%$. Rf 0.47 (cyclohexane/EtOAc: 7/3). IR (neat) $v_{\max } / \mathrm{cm}^{-1}: 2931,1591,1421,1267,1204,1154,1062,906$, 729, 648. ${ }^{1} \mathrm{H}$ NMR $\left(300 \mathrm{MHz}, \mathrm{CDCl}_{3}\right) \delta 6.98(\mathrm{~d}, J=8.5 \mathrm{~Hz}, 1 \mathrm{H}), 6.66(\mathrm{~d}, J=8.5 \mathrm{~Hz}, 1 \mathrm{H}), 6.49-6.40(\mathrm{~m}, 3 \mathrm{H}), 6.00(\mathrm{t}$, $J=4.7 \mathrm{~Hz}, 1 \mathrm{H}), 3.88(\mathrm{~s}, 3 \mathrm{H}), 3.79(\mathrm{~s}, 6 \mathrm{H}), 3.12-2.94(\mathrm{~m}, 2 \mathrm{H}), 2.49-2.28(\mathrm{~m}, 2 \mathrm{H}) .{ }^{13} \mathrm{C} \mathrm{NMR}\left(75 \mathrm{MHz}, \mathrm{CDCl}_{3}\right) \delta$ 160.62 (2C), 154.9, 142.8, 139.2, 138.1, 129.7, 125.5, 115.8, 113.6, 108.8, 106.9 (2C), 99.4, 56.3, 55.3 (2C), 28.1, 23.0. MS (APCI, m/z) $375.15\left([\mathrm{M}+\mathrm{H}]^{+},{ }^{79} \mathrm{Br}\right), 377.36\left([\mathrm{M}+\mathrm{H}]^{+},{ }^{81} \mathrm{Br}\right)$. Anal. Calcd for $\mathrm{C}_{19} \mathrm{H}_{19} \mathrm{BrO}_{3}: \mathrm{C} 60.81$, H 5.10, found C 60.54, H 4.99 .

4.4.3. 7-Methoxy-4-(3,4,5-trimethoxyphenyl)-1,2-dihydronaphtalene (1c)

Yield: 75\%. Rf 0.57 (cyclohexane/EtOAc: 8/2). IR (neat) $v_{\max } / \mathrm{cm}^{-1}: 2934,2834,1589,1496,1453,1421,1358,1301$, 1278, 1249, 1203, 1150, 1117, 1062, 1039, 1000. ${ }^{1} \mathrm{H}$ NMR $\left(300 \mathrm{MHz}, \mathrm{CDCl}_{3}\right) \delta 6.93(\mathrm{~d}, J=8.5 \mathrm{~Hz}, 1 \mathrm{H}), 6.71(\mathrm{~d}, J=$ $2.6 \mathrm{~Hz}, 1 \mathrm{H}), 6.59(\mathrm{dd}, J=2.6 \mathrm{~Hz}, J=8.5 \mathrm{~Hz}, 1 \mathrm{H}), 6.49(\mathrm{~s}, 2 \mathrm{H}), 5.89$ (t, $J=4.7 \mathrm{~Hz}, 1 \mathrm{H}), 3.82(\mathrm{~s}, 3 \mathrm{H}), 3.77(\mathrm{~s}, 6 \mathrm{H}), 3.74$ $(\mathrm{s}, 3 \mathrm{H}), 2.76(\mathrm{t}, J=7.9 \mathrm{~Hz}, 2 \mathrm{H}), 2.31(\mathrm{~m}, 2 \mathrm{H}) .{ }^{13} \mathrm{C} \mathrm{NMR}\left(75 \mathrm{MHz}, \mathrm{CDCl}_{3}\right) \delta 158.6,152.9,139.5,138.6(2 \mathrm{C}), 137.1$, 136.7, 128.1, 126.7, 124.8, 113.8, 110.8, 105.7 (2C), 60.9, 56.1 (2C), 55.3, 28.8, 23.4. MS (APCI, m/z) 327.9 [M + $\mathrm{H}]+$. Anal. Calcd for $\mathrm{C}_{20} \mathrm{H}_{22} \mathrm{O}_{4}$ : C 73.60, H 6.79, found C 73.54, H 6.69.

4.4.4. 6-Bromo-7-methoxy-4-(3,4,5-trimethoxyphenyl)-1,2-dihydronaphtalene (1k)

Yield: $78 \%$. Rf 0.47 (cyclohexane/EtOAc: 8/2). IR (neat) $v_{\max } / \mathrm{cm}^{-1}: 2934,2833,1580,1505,1490,1465,1449,1411$, 1360, 1337, 1255, 1237, 1166, 1126, 1018, 1003, 907, 730, 646. ${ }^{1} \mathrm{H}$ NMR $\left(300 \mathrm{MHz}, \mathrm{CDCl}_{3}\right) \delta 6.78(\mathrm{~s}, 1 \mathrm{H}), 6.66(\mathrm{~s}$, $1 \mathrm{H}), 6.53(\mathrm{~s}, 2 \mathrm{H}), 6.00(\mathrm{t}, J=4.6 \mathrm{~Hz}, 1 \mathrm{H}), 3.92(\mathrm{~s}, 3 \mathrm{H}), 3.90(\mathrm{~s}, 3 \mathrm{H}), 3.85(\mathrm{~s}, 6 \mathrm{H}), 2.81(\mathrm{t}, J=7.8 \mathrm{~Hz}, 2 \mathrm{H}), 2.39(\mathrm{~m}$, 2H). ${ }^{13} \mathrm{C} \mathrm{NMR}\left(75 \mathrm{MHz}, \mathrm{CDCl}_{3}\right) \delta 154.5,153.1$ (2C), 138.7, 137.7, 137.3, 135.9, 130.1, 129.3, 125.7, 111.7, 108.6, 105.6 (2C), 60.9, 56.3, 56.1 (2C), 28.5, 23.2. MS (APCI, m/z) 405,1 ([M+H]+, 79 Br ), $407.4\left([\mathrm{M}+\mathrm{H}]^{+,}, 81 \mathrm{Br}\right)$. Anal. Calcd for $\mathrm{C}_{20} \mathrm{H}_{21} \mathrm{BrO}_{4}$ : C 59.27, H 5.22, found C 59.00, H 5.03.

4.5. Synthesis of $\mathbf{3 a}$ and $\mathbf{3 b}$.

A $\mathrm{CH}_{2} \mathrm{Cl}_{2}$ solution $(30 \mathrm{~mL})$ of $1 \mathbf{a}$ or $1 \mathrm{c}(500 \mathrm{mg}, 4.93 \mathrm{mmol})$ and DDQ $(1.34 \mathrm{~g}, 5.91 \mathrm{mmol})$ was stirred at room temperature for $1 \mathrm{~h}$. The medium was next washed three times with water and brine. The organic layer was dryed over $\mathrm{MgSO}_{4}$, filtered and evaporated to dryness. Purification by flash chromatography afforded 3a,b.

4.5.1. 1-Bromo-2-methoxy-5-(3,4,5-trimethoxyphenyl)naphthalene (3a)

Yield: $33 \%$. Rf 0.42 (cyclohexane/EtOAc: 7/3). IR (neat) $v_{\max } / \mathrm{cm}^{-1}: 3663,3324,2974,2934,1672,1659,1579,1499$, 1088, 1045, 730, 700. ${ }^{1} \mathrm{H}$ NMR $\left(300 \mathrm{MHz}, \mathrm{CDCl}_{3}\right) \delta 8.28(\mathrm{~d}, J=8.6 \mathrm{~Hz}, 1 \mathrm{H}), 7.92(\mathrm{~d}, J=9.2 \mathrm{~Hz}, 1 \mathrm{H}), 7.59(\mathrm{dd}, J=$ 8.6, 7.0 Hz, 1H), 7.35 (dd, $J=7.0,1.1 \mathrm{~Hz}, 1 \mathrm{H}), 7.23$ (d, J=9.4 Hz, 1H), 6.66 (s, 2H), 4.03 (s, 3H), 3.95 (s, $3 \mathrm{H}), 3.87$ (s, $6 \mathrm{H}) .{ }^{13} \mathrm{C}$ NMR $\left(75 \mathrm{MHz}, \mathrm{CDCl}_{3}\right) \delta 153.8,153.1$ (2C), 140.7, 137.5, 136.2, 133.6, 128.3, 127.5, 127.3, 126.0, 125.3, 113.5, 109.1, 107.4 (2C), 61.1, 57.1, 56.3 (2C). MS (APCI, m/z) 403.1 ([M+H] $\left.{ }^{+,} 79 \mathrm{Br}\right), 405.1\left([\mathrm{M}+\mathrm{H}]^{+,}{ }^{81} \mathrm{Br}\right)$. Anal. Calcd for $\mathrm{C}_{20} \mathrm{H}_{19} \mathrm{BrO}_{4}$ : C 59.57, $\mathrm{H} 4.75$, found C 59.41, $\mathrm{H} 4.63$.

4.5.2. 6-Methoxy-1-(3,4,5-trimethoxyphenyl)naphtalene (3b)

Yield: $99 \%$. Rf 0.3 (cyclohexane/EtOAc: 8/2). IR (neat) $v_{\max } / \mathrm{cm}^{-1}: 2934,1672,1579,1499,1410,1374,1335,1235$, 1168, 1124, 1031, 1007, 910, 835, 789, 730, 700, 667, 647. ${ }^{1} \mathrm{H}$ NMR $\left(300 \mathrm{MHz}, \mathrm{CDCl}_{3}\right) \delta 7.86(\mathrm{~d}, J=9.3 \mathrm{~Hz}, 1 \mathrm{H})$, $7.75(\mathrm{~d}, J=8.2 \mathrm{~Hz}, 1 \mathrm{H}), 7.48(\mathrm{t}, J=7.5 \mathrm{~Hz}, 1 \mathrm{H}), 7.30(\mathrm{~d}, J=7.1 \mathrm{~Hz}, 1 \mathrm{H}), 7.21(\mathrm{~d}, J=1.9 \mathrm{~Hz}, 1 \mathrm{H}), 7.12(\mathrm{dd}, J=9.3$ $\mathrm{Hz}, J=1.9 \mathrm{~Hz}, 1 \mathrm{H}), 6.70(\mathrm{~s}, 2 \mathrm{H}), 3.95(\mathrm{~s}, 6 \mathrm{H}), 3.88(\mathrm{~s}, 6 \mathrm{H}) .{ }^{13} \mathrm{C} \mathrm{NMR}\left(75 \mathrm{MHz}, \mathrm{CDCl}_{3}\right) \delta 157.5,152.9(2 \mathrm{C}), 140.2$, 137.3, 136.5, 135.1, 127.6, 127.1, 126.5, 125.9, 124.5, 118.7, 107.2 (2C), 106.1, 60.9, 56.2 (2C), 55.3. MS (APCI, m/z) $325.2[\mathrm{M}+\mathrm{H}]^{+}$. Anal. Calcd for $\mathrm{C}_{20} \mathrm{H}_{20} \mathrm{O}_{4}$ : C 74.06, H 6.21, found C 73.80, H 6.13.

4.6. General procedure for the preparation of anilines $\mathbf{1 d}, \mathbf{1 i}, \mathbf{1 l}$ and $\mathbf{3 c}$.

A solution of $\mathbf{1 a}, \mathbf{1 b}, \mathbf{1 k}$ or $\mathbf{3 a}(1 \mathrm{mmol}), \mathrm{NaN}_{3}(2 \mathrm{mmol}), \mathrm{CuI}(0.1 \mathrm{mmol})$, DMEDA $(0.15 \mathrm{mmol})$ and sodium ascorbate $0.05 \mathrm{mmol}$ ) in a mixture of DMSO/ $\mathrm{H}_{2} \mathrm{O}: 5 / 1$ was stirred at $60{ }^{\circ} \mathrm{C}$ in a sealed tube. After $12 \mathrm{~h}$, the medium was cooled, 
quenched with $\mathrm{NH}_{4} \mathrm{Cl}$ and extracted with EtOAc $(3 \times 10 \mathrm{~mL})$. The combined organic layers were dried over $\mathrm{MgSO}_{4}$, filtered and evaporated to dryness. Purification by flash chromatography afforded compounds $\mathbf{1 d ,} \mathbf{1 i}, \mathbf{1 l}$ and $\mathbf{3 c}$.

4.6.1. 2-Methoxy-5-(3,4,5-trimethoxyphenyl)-7,8-dihydronahtalen-1-amine (1d)

Yield: $59 \%$. Rf 0.6 (cyclohexane/EtOAc: 5/5). IR (neat) $v_{\max } / \mathrm{cm}^{-1}: 3663,3324,2974,1659,1088,1045 .{ }^{1} \mathrm{H}$ NMR (300 $\left.\mathrm{MHz} \mathrm{CDCl}_{3}\right) \delta 6.52(\mathrm{~d}, J=8.4 \mathrm{~Hz}, 1 \mathrm{H}), 6.48(\mathrm{~s}, 2 \mathrm{H}), 6.43(\mathrm{~d}, J=8.4 \mathrm{~Hz}, 1 \mathrm{H}), 5.84(\mathrm{t}, J=4.6 \mathrm{~Hz}, 1 \mathrm{H}), 3.81(\mathrm{~s}, 3 \mathrm{H})$,

$3.77(\mathrm{~s}, 3 \mathrm{H}), 3.76(\mathrm{~s}, 6 \mathrm{H}), 2.60(\mathrm{t}, J=7.9 \mathrm{~Hz}, 2 \mathrm{H}), 2.34(\mathrm{~m}, 2 \mathrm{H}), \mathrm{NH}_{2}$ not seen. ${ }^{13} \mathrm{C} \mathrm{NMR}\left(75 \mathrm{MHz}, \mathrm{CDCl}_{3}\right) \delta 152.9$ (2C), 147.2, 140.1, 137.3, 132.7, 128.3, 124.2, 121.2, 116.7, 107.2, 106.2 (2C), 61.0, 56.2 (2C), 55.7, 23.0, 21.7 (1C missing). MS (APCI, m/z) 342.2 [M + H] $]^{+}$. Anal. Calcd for $\mathrm{C}_{20} \mathrm{H}_{23} \mathrm{NO}_{4}$ : C 70.36, H 6.79, N 4.10 found C 70.01, H 6.48, N 3.98 .

4.6.2. 5-(3,5-Dimethoxyphenyl)-1-amino-2-methoxy-1,2-dihydronaphtalene (1i)

Yield: $73 \%$. Rf 0.8 (cyclohexane/EtOAc: 7/3). IR (neat) $v_{\max } / \mathrm{cm}^{-1}: 3669,3324,2974,1670,1088,1045 .{ }^{1} \mathrm{H}$ NMR (300 $\left.\mathrm{MHz} \mathrm{CDCl}_{3}\right) \delta 6.49-6.42(\mathrm{~m}, 4 \mathrm{H}), 6.35(\mathrm{t}, J=2.3 \mathrm{~Hz}, 1 \mathrm{H}), 5.84(\mathrm{t}, J=4.6 \mathrm{~Hz}, 1 \mathrm{H}), 3.75(\mathrm{~s}, 3 \mathrm{H}), 3.72(\mathrm{~m}, 2 \mathrm{H}), 3.69(\mathrm{~s}$, $6 \mathrm{H}), 2.58(\mathrm{t}, J=7.9 \mathrm{~Hz}, 2 \mathrm{H}), 2.32(\mathrm{~m}, 2 \mathrm{H}) .{ }^{13} \mathrm{C} \mathrm{NMR}\left(75 \mathrm{MHz}, \mathrm{CDCl}_{3}\right) \delta 160.5(2 \mathrm{C}), 147.2,143.8,140.1,132.7,128.2$, 124.3, 121.2, 116.8, 107.0 (3C), 99.4, 55.7, 55.5 (2C), 23.0, 21.7. MS (APCI, m/z) 312.9 [M + H] $]^{+}$Anal. Calcd for $\mathrm{C}_{19} \mathrm{H}_{21} \mathrm{NO}_{3}$ : C 73.29, $\mathrm{H} 6.80, \mathrm{~N} 4.50$ found C 73.04, H 6.62, N 4.40.

4.6.3. 3-Methoxy-8-(3,4,5-trimethoxyphenyl)-5,6-dihydronaphtalen-2-amine (11)

Yield: $72 \%$. Rf 0.6 (cyclohexane/EtOAc: 5/5). IR (neat) $v_{\max } / \mathrm{cm}^{-1}:$ 2934, 2251, 2157, 1978, 1578, 1508, 1462, 1410, 1366, 1339, 1285, 1243, 1214, 1158, 1124, 1006, 909, 823, 731. ${ }^{1} \mathrm{H}$ NMR $\left(300 \mathrm{MHz}, \mathrm{CDCl}_{3}\right) \delta 6.68(\mathrm{~s}, 1 \mathrm{H}), 6.55(\mathrm{~s}$, 2H), $6.49(\mathrm{~s}, 1 \mathrm{H}), 5.94(\mathrm{t}, J=4.6 \mathrm{~Hz}, 1 \mathrm{H}), 3.89(\mathrm{~s}, 3 \mathrm{H}), 3.87(\mathrm{~s}, 3 \mathrm{H}), 3.84(\mathrm{~s}, 6 \mathrm{H}), 2.76(\mathrm{t}, J=7.7 \mathrm{~Hz}, 2 \mathrm{H}), 2.35(\mathrm{~m}$, $2 \mathrm{H}), \mathrm{NH}_{2}$ not seen. ${ }^{13} \mathrm{C} \mathrm{NMR}\left(75 \mathrm{MHz}, \mathrm{CDCl}_{3}\right) 153.0$ (2C), 146.5, 145.9, 139.7, 137.1, 133.4, 128.0, 127.8, 125.2, 113.6, 110.5, 105.9 (2C), 61.0, 56.3 (2C), 55.8, 28.2, 23.9. MS (APCI, m/z) 342.0 [M + H] $]^{+}$Anal. Calcd for $\mathrm{C}_{20} \mathrm{H}_{23} \mathrm{NO}_{4}$ : C 70.36, H 6.79, N 4.10 found C 69.88, H 6.39, N 3.89.

4.6.4. 2-Methoxy-5-(3,4,5-trimethoxyphenyl)naphtalen-1-amine (3c)

Yield: $46 \%$. Rf 0.33 (cyclohexane/EtOAc: 7/3). IR (neat) $v_{\max } / \mathrm{cm}^{-1}: 3663,3324,2974,2934,1672,1659,1579,1088$, 1045. ${ }^{1} \mathrm{H}$ NMR $\left(300 \mathrm{MHz}, \mathrm{CDCl}_{3}\right) \delta 7.72(\mathrm{~d}, J=8.5 \mathrm{~Hz}, 1 \mathrm{H}), 7.36(\mathrm{~m}, 2 \mathrm{H}), 7.20(\mathrm{~d}, J=7.0 \mathrm{~Hz}, 1 \mathrm{H}), 7.12(\mathrm{~d}, J=9.2$ $\mathrm{Hz}, 1 \mathrm{H}), 6.62$ (s, 2H), 4.27 (br s, 2H), 3.89 (s, 3H), 3.87 (s, 3H), 3.79 (s, 6H). ${ }^{13} \mathrm{C} \mathrm{NMR}\left(75 \mathrm{MHz}, \mathrm{CDCl}_{3}\right) \delta 153.1(2 \mathrm{C})$, 142.6, 140.8, 137.2, 137.0, 129.8, 127.7, 124.6 (2C), 124.4, 120.1, 116.9, 113.4, 107.3 (2C), 61.1, 56.7, 56.3 (2C). MS $\left(\right.$ APCI, m/z) $362[\mathrm{M}+\mathrm{Na}]^{+}$. Anal. Calcd for $\mathrm{C}_{20} \mathrm{H}_{21} \mathrm{NO}_{4}: \mathrm{C}$ 70.78, H 6.24, N 4.13, found C 70.55, H 6.15, N 4.01.

4.7. General procedure for the preparation of naphtols $\mathbf{1 e}, \mathbf{1 h}$ and $\mathbf{3 d}$.

A solution of 1a,b, and $\mathbf{3 a}(1 \mathrm{mmol}), \mathrm{KOH}(5 \mathrm{mmol}), \mathrm{Pd}_{2} \mathrm{dba}_{3}(0.1 \mathrm{mmol})$ and $t \mathrm{BuXPhos}(0.2 \mathrm{mmol})$ in a mixture of dioxane/ $\mathrm{H}_{2} \mathrm{O}$ : $1 / 1$ was stirred at $90{ }^{\circ} \mathrm{C}$ in a sealed tube. After $1 \mathrm{~h}$, the medium was cooled to room temperature, quenched with $\mathrm{NH}_{4} \mathrm{Cl}$ and extracted with EtOAc $(3 \times 10 \mathrm{~mL})$. The combined organic layers were then dried over $\mathrm{MgSO}_{4}$, filtered and evaporated to dryness. Purification by flash chromatography afforded compounds $\mathbf{1 e}, \mathbf{1 h}$ and $\mathbf{3 d}$.

4.7.1. 2-Methoxy-5-(3,4,5-trimethoxyphenyl)-7,8-dihydronaphtalen-1-ol (1e)

Yield: $63 \%$. Rf 0.52 (cyclohexane/EtOAc: 7/3). IR (neat) $v_{\max } / \mathrm{cm}^{-1}: 2941,2177,1581,1489,1355,1234,1126,905$, 726, 652, 610. ${ }^{1} \mathrm{H}$ NMR $\left(300 \mathrm{MHz}, \mathrm{CDCl}_{3}\right) \delta 6.63(\mathrm{~d}, J=8.5 \mathrm{~Hz}, 1 \mathrm{H}), 6.59(\mathrm{~d}, J=8.5 \mathrm{~Hz}, 1 \mathrm{H}), 6.56(\mathrm{~s}, 2 \mathrm{H}), 5.97$ (t, $J$ $=4.6 \mathrm{~Hz}, 1 \mathrm{H}), 5.72(\mathrm{~s}, 1 \mathrm{H}), 3.89(\mathrm{~s}, 6 \mathrm{H}), 3.84(\mathrm{~s}, 6 \mathrm{H}), 2.89(\mathrm{t}, J=7.9 \mathrm{~Hz}, 2 \mathrm{H}), 2.38(\mathrm{~m}, 2 \mathrm{H}) .{ }^{13} \mathrm{C} \mathrm{NMR}(75 \mathrm{MHz}$, $\left.\mathrm{CDCl}_{3}\right) \delta 153.0$ (2C), 146.0, 142.1, 139.7, 137.0, 129.1, 125.5, 122.4, 117.6, 107.4, 106.1 (2C), 61.1, 56.3 (2C), 56.1, 23.0, 20.4, (1 C missing). MS (APCI, m/z) 343.2 [M+ H] $]^{+}$. Anal. Calcd for $\mathrm{C}_{20} \mathrm{H}_{22} \mathrm{O}_{5}$ : C 70.16, H 6.48, found C 70.00, H 6.32 .

4.7.2. 5-(3,5-Dimethoxyphenyl)-2-methoxy-7,8-dihydronaphtalen-1-ol (1h)

Yield: $62 \%$. Rf 0.46 (cyclohexane/EtOAc: 7/3). IR (neat) $v_{\max } / \mathrm{cm}^{-1}:$ 2934, 1590, 1489, 1353, 1276, 1204, 1152, 1095, 1069, 826. ${ }^{1} \mathrm{H}$ NMR $\left(300 \mathrm{MHz}, \mathrm{CDCl}_{3}\right) \delta 6.60(\mathrm{~s}, 1 \mathrm{H}), 6.58(\mathrm{~d}, J=2.3 \mathrm{~Hz}, 1 \mathrm{H}), 6.50(\mathrm{~d}, J=2.3 \mathrm{~Hz}, 2 \mathrm{H}), 6.44(\mathrm{t}, J=$ 
$2.3 \mathrm{~Hz}, 1 \mathrm{H}), 5.98(\mathrm{t}, J=4.7 \mathrm{~Hz}, 1 \mathrm{H}), 5.71(\mathrm{~s}, 1 \mathrm{H}), 3.88(\mathrm{~s}, 3 \mathrm{H}), 3.79(\mathrm{~s}, 6 \mathrm{H}), 2.88(\mathrm{t}, J=8.0 \mathrm{~Hz}, 2 \mathrm{H}), 2.37(\mathrm{~m}, 2 \mathrm{H}) .{ }^{13} \mathrm{C}$ NMR (75 MHz, $\left.\mathrm{CDCl}_{3}\right) \delta 160.6$ (2C), 145.9, 143.4, 142.1, 140.0, 129.0, 125.7, 122.4, 117.6, 107.4, 107.0 (2C), 99.5, 56.1, 55.5 (2C), 23.0, 20.4. MS (APCI, m/z) 313.2 [M + H $]^{+}$. Anal. Calcd for $\mathrm{C}_{19} \mathrm{H}_{20} \mathrm{O}_{4}$ : C 73.06, H 6.45, found C 72.99, H 6.39 .

\subsubsection{2-Methoxy-5-(3,4,5-trimethoxyphenyl)naphtalen-1-ol (3d)}

Yield: $82 \%$. Rf 0.39 (cyclohexane/EtOAc: 7/3). IR (neat) $v_{\max } / \mathrm{cm}^{-1}:$ 2936, 1579, 1500, 1461, 1403, 1340, 1235, 1123, 1073, 1005, 896, 797, 729. ${ }^{1} \mathrm{H}$ NMR $\left(300 \mathrm{MHz}, \mathrm{CDCl}_{3}\right) \delta 8.20(\mathrm{~d}, J=7.0 \mathrm{~Hz}, 1 \mathrm{H}), 7.53-7.44(\mathrm{~m}, 2 \mathrm{H}), 7.31(\mathrm{dd}, J=$ $7.0 \mathrm{~Hz}, J=1.2 \mathrm{~Hz}, 1 \mathrm{H}), 7.22(\mathrm{~d}, J=9.3 \mathrm{~Hz}, 1 \mathrm{H}), 6.70(\mathrm{~s}, 2 \mathrm{H}), 4.00(\mathrm{~s}, 3 \mathrm{H}), 3.94(\mathrm{~m}, 3 \mathrm{H}), 3.87$ (s, 6H), OH not seen. ${ }^{13} \mathrm{C}$ NMR $\left(75 \mathrm{MHz}, \mathrm{CDCl}_{3}\right) \delta 153.0$ (2C), 141.2, 139.9, 139.8, 137.2, 136.8, 127.8, 125.2, 125.0, 124.5, 121.0, 118.0, 113.1, 107.3 (2C), 61.1, 57.2, 56.3 (2C). MS (APCI, m/z) $341[\mathrm{M}+\mathrm{H}]^{+}$. Anal. Calcd for $\mathrm{C}_{20} \mathrm{H}_{20} \mathrm{O}_{5}: \mathrm{C} 70.57, \mathrm{H}$ 5.92, found C 70.30, H 5.67.

4.8. General procedure for the synthesis of alkynes $\mathbf{1 f}, \mathbf{1 g}, \mathbf{3 e}$ and $\mathbf{3 f}$.

A DMF solution of 1a and 3a $(1 \mathrm{mmol})$, alkyne (1.2 mmol), $\mathrm{PdCl}_{2}\left(\mathrm{PPh}_{3}\right)_{2}(0.05 \mathrm{mmol}), \mathrm{PPh}_{3}(0.1 \mathrm{mmol}), \mathrm{CuI}(0.05$ $\mathrm{mmol})$ and $\mathrm{Et}_{2} \mathrm{NH}(2 \mathrm{mmol})$ was stirred at $120{ }^{\circ} \mathrm{C}$ under microwave irradiation. After 25 min, the medium was cooled down to room temperature, quenched with $\mathrm{NH}_{4} \mathrm{Cl}$ and extracted with EtOAc $(3 \times 10 \mathrm{~mL})$. The combined organic layers were then dried over $\mathrm{MgSO}_{4}$, filtered and evaporated to dryness. Purification by flash chromatography afforded compounds 1f, 1g, $\mathbf{3 e}$ and $3 f$.

4.8.1. 4-(2-Methoxy-5-(3,4,5-trimethoxyphenyl)-7,8-dihydronaphtalen-1-ul)but-3-yn-1-ol (1f)

Yield: $41 \%$. Rf 0.6 (cyclohexane/EtOAc: 4/6). IR (neat) $v_{\max } / \mathrm{cm}^{-1}: 2922,1590,1489,1413,1353,1267,1128,905$, 812, 738. ${ }^{1} \mathrm{H}$ NMR $\left(300 \mathrm{MHz}, \mathrm{CDCl}_{3}\right) \delta 6.97(\mathrm{~d}, J=8.6 \mathrm{~Hz}, 1 \mathrm{H}), 6.63(\mathrm{~d}, J=8.6 \mathrm{~Hz}, 1 \mathrm{H}), 6.53(\mathrm{~s}, 2 \mathrm{H}), 5.98(\mathrm{t}, J=4.5$ Hz, 1H), 3.89 (s, 3H), 3.87 (s, 3H), $3.84(\mathrm{~m}, 8 \mathrm{H}), 3.02$ (t, J= $7.8 \mathrm{~Hz}, 2 \mathrm{H}), 2.81(\mathrm{t}, J=6.0 \mathrm{~Hz}, 2 \mathrm{H}), 2.39(\mathrm{~m}, 2 \mathrm{H}), \mathrm{OH}$ not seen. ${ }^{13} \mathrm{C}$ NMR (75 MHz, $\left.\mathrm{CDCl}_{3}\right) 159.3$ (2C), 152.9, 140.6, 139.2, 137.1, 136.5, 128.2, 126.2, 125.3, 111.2 (2C), 107.3, 105.7, 95.1, 77.7, 61.1, 60.9, 56.1, 55.8 (2C), 26.3, 24.4, 23.0. MS (APCI, m/z) 395.6 [M + H] ${ }^{+}$. Anal. Calcd for $\mathrm{C}_{24} \mathrm{H}_{26} \mathrm{O}_{5}$ : C 73.08, H 6.64, found C 72.79, H 6.38.

4.8.2. 3-(2-Methoxy-5-(3,4,5-trimethoxyphenyl)-7,8-dihydronaphtalen-1-yl)prop-2-yn-1-ol (1g)

Yield: $25 \%$. Rf 0.57 (cyclohexane/EtOAc: 4/6). IR (neat) $v_{\max } / \mathrm{cm}^{-1}: 2922,1590,1489,1413,1353,1267,1128,905$, 805, 726, 649. ${ }^{1} \mathrm{H}$ NMR $\left(300 \mathrm{MHz}, \mathrm{CDCl}_{3}\right) \delta 7.00(\mathrm{~d}, J=8.6 \mathrm{~Hz}, 1 \mathrm{H}), 6.64(\mathrm{~d}, J=8.6 \mathrm{~Hz}, 1 \mathrm{H}), 6.53(\mathrm{~s}, 2 \mathrm{H}), 5.99$ (t, $J$ $=4.3 \mathrm{~Hz}, 1 \mathrm{H}), 4.61(\mathrm{~s}, 2 \mathrm{H}), 3.89(\mathrm{~s}, 3 \mathrm{H}), 3.87(\mathrm{~s}, 3 \mathrm{H}), 3.84(\mathrm{~s}, 6 \mathrm{H}), 3.04(\mathrm{t}, J=7.7 \mathrm{~Hz}, 2 \mathrm{H}), 2.38-2.19(\mathrm{~m}, 2 \mathrm{H}) . \mathrm{OH}$ not seen. ${ }^{13} \mathrm{C}$ NMR (75 MHz, $\mathrm{CDCl}_{3}$ ) 159.3, 152.9 (2C), 141.2, 139.1, 137.1, 136.5, 127.9, 126.7, 125.4, 110.4, 107.4, 105.8 (2C), 95.8, 80.2, 60.9, 56.1 (2C), 55.8, 51.9, 26.2, 22.9. MS (APCI, m/z) $381.8[\mathrm{M}+\mathrm{H}]^{+}$. Anal. Calcd for $\mathrm{C}_{23} \mathrm{H}_{24} \mathrm{O}_{5}$ : C 72.61, H 6.36, found C 72.56, H 6.12.

4.8.3. 3-(2-Methoxy-5-(3,4,5-trimethoxyphenyl)naphtalen-1-yl)but-3-yn-1-ol (3e)

Yield: $52 \%$. Rf 0.22 (cyclohexane/EtOAc: 6/4). IR (neat) $v_{\max } / \mathrm{cm}^{-1}:$ 2934, 1580, 1501, 1463, 1409, 1320, 1266, 1236, 1183, 1124, 1060, 1005, 910, 850, 730, 686. ${ }^{1} \mathrm{H}$ NMR $\left(300 \mathrm{MHz}, \mathrm{CDCl}_{3}\right) \delta 8.27(\mathrm{~d}, J=8.4 \mathrm{~Hz}, 1 \mathrm{H}), 7.90(\mathrm{~d}, J=9.4$ $\mathrm{Hz}, 1 \mathrm{H}), 7.60-7.48(\mathrm{~m}, 1 \mathrm{H}), 7.31(\mathrm{~d}, J=6.8 \mathrm{~Hz}, 1 \mathrm{H}), 7.19$ (d, J=9.4 Hz, 1H), $6.66(\mathrm{~s}, 2 \mathrm{H}), 4.01(\mathrm{~s}, 3 \mathrm{H}), 3.98-3.89$ $(\mathrm{m}, 5 \mathrm{H}), 3.87(\mathrm{~s}, 6 \mathrm{H}), 2.92(\mathrm{t}, J=6.1 \mathrm{~Hz}, 2 \mathrm{H}), \mathrm{OH}$ not seen. ${ }^{13} \mathrm{C} \mathrm{NMR}\left(75 \mathrm{MHz}, \mathrm{CDCl}_{3}\right) 158.7,152.9(2 \mathrm{C}), 140.5$, 137.3, 136.2, 134.9, 127.9, 126.8, 126.7, 124.9 (2C), 112.4, 107.3 (2C), 106.5, 96.4, 77.3, 61.2, 60.9, 56.5, 56.2 (2C), 24.6. MS (APCI, m/z) $393.3[\mathrm{M}+\mathrm{H}]^{+}$. Anal. Calcd for $\mathrm{C}_{24} \mathrm{H}_{24} \mathrm{O}_{5}: \mathrm{C} 73.45, \mathrm{H}$ 6.16, found C 73.34, $\mathrm{H} 6.02$. 4.8.4. 3-(2-Methoxy-5-(3,4,5-trimethoxyphenyl)naphthalen-1-yl)prop-2-yn-1-ol (3f)

Yield: $49 \%$. Rf 0.14 (cyclohexane/EtOAc: 2/8). IR (neat) $v_{\max } / \mathrm{cm}^{-1}: 2922,1501,1463,1413,1267,1128,905,805$, 726, 649. ${ }^{1} \mathrm{H} \mathrm{NMR}\left(300 \mathrm{MHz}, \mathrm{CDCl}_{3}\right) \delta 8.35(\mathrm{~d}, J=8.4 \mathrm{~Hz}, 1 \mathrm{H}), 8.00(\mathrm{~d}, J=9.4 \mathrm{~Hz}, 1 \mathrm{H}), 7.63(\mathrm{dd}, J=8.4 \mathrm{~Hz}, J=7.0$ $\mathrm{Hz}, 1 \mathrm{H}), 7.39$ (d, $J=7.0 \mathrm{~Hz}, 1 \mathrm{H}), 7.26$ (d, $J=9.5 \mathrm{~Hz}, 1 \mathrm{H}), 6.73(\mathrm{~s}, 2 \mathrm{H}), 4.80$ (s, 2H), 4.08 (s, 3H), 4.01 (s, 3H), $3.94(\mathrm{~s}$, $6 \mathrm{H})$, $\mathrm{OH}$ not seen. ${ }^{13} \mathrm{C} \mathrm{NMR}\left(75 \mathrm{MHz}, \mathrm{CDCl}_{3}\right)$ 158.1 (2C), 152.1, 139.8, 135.3, 134.2, 127.9, 126.1, 125.9, 124.2, 
124.0, 115.5, 106.3 (2C), 96.2, 79.3, 60.2, 55.6, 55.4 (2C), 51.3, two C missing. MS (APCI, m/z) $379.5[\mathrm{M}+\mathrm{H}]^{+}$. Anal. Calcd for $\mathrm{C}_{23} \mathrm{H}_{22} \mathrm{O}_{5}$ : C 73.00, H 5.86, found C 72.87, H 5.76.

4.9. General procedure for the synthesis of compounds $\mathbf{1} \mathbf{j}$ and $\mathbf{3} \mathbf{g}$.

A NMP solution of $1 \mathbf{a}$ or $3 \mathbf{a}(1 \mathrm{mmol})$, methyl acrylate $(10 \mathrm{mmol})$, PEPPSI $(0.05 \mathrm{mmol})$ and $\mathrm{K}_{2} \mathrm{CO}_{3}(2 \mathrm{mmol})$ was stirred at $140{ }^{\circ} \mathrm{C}$ in a sealed tube. After $1 \mathrm{~h}$, the medium was cooled down to room temperature, quenched with $\mathrm{NH}_{4} \mathrm{Cl}$ and extracted with EtOAc ( 3 x $10 \mathrm{~mL}$ ). The combined organic layers were then dried over $\mathrm{MgSO}_{4}$, filtered, and the solvent was then removed. Purification by flash chromatography afforded compounds $\mathbf{1} \mathbf{j}$ and $\mathbf{3 g}$.

4.9.1. Methyl-3-(2-methoxy-5-(3,4,5-trimethoxyphenyl)-7,8-dihydronaphtalen-1-yl)acrylate (1j)

Yield: $35 \% .0 .41$ Rf (cyclohexane/EtOAc: 7/3). IR (neat) $v_{\max } / \mathrm{cm}^{-1}: 2945,2500,1714,1579,1504,1463,1412,1352$, 1252, 1169, 1124, 1007, 911. ${ }^{1} \mathrm{H}$ NMR $\left(300 \mathrm{MHz} \mathrm{CDCl}_{3}\right) \delta 7.99(\mathrm{~d}, J=16.2 \mathrm{~Hz}, 1 \mathrm{H}), 7.05(\mathrm{~d}, J=8.6 \mathrm{~Hz}, 1 \mathrm{H}), 6.69(\mathrm{~d}$, $J=8.6 \mathrm{~Hz}, 1 \mathrm{H}), 6.53(\mathrm{~s}, 2 \mathrm{H}), 6.45(\mathrm{~d}, J=16.2 \mathrm{~Hz}, 1 \mathrm{H}), 6.01(\mathrm{t}, J=4.1 \mathrm{~Hz}, 1 \mathrm{H}), 3.88(\mathrm{~s}, 3 \mathrm{H}), 3.84(\mathrm{~s}, 3 \mathrm{H}), 3.83(\mathrm{~s}, 6 \mathrm{H})$, $3.81(\mathrm{~s}, 3 \mathrm{H}), 2.96(\mathrm{t}, J=7.7 \mathrm{~Hz}, 2 \mathrm{H}), 2.33(\mathrm{~m}, 2 \mathrm{H}) .{ }^{13} \mathrm{C} \mathrm{NMR}\left(75 \mathrm{MHz}, \mathrm{CDCl}_{3}\right)$ 167.9, 157.7, 153.0 (2C), 139.6, 139.1, 138.1, 137.1, 136.7, 128.6, 127.9, 125.1, 123.4, 121.8, 107.8, 105.8 (2C), 60.9, 56.1 (2C), 55.5, 51.6, 25.3, 23.2. MS (APCI, m/z) $411.8[\mathrm{M}+\mathrm{H}]^{+}$. Anal. Calcd for $\mathrm{C}_{24} \mathrm{H}_{26} \mathrm{O}_{6}: \mathrm{C} 70.23, \mathrm{H} 6.38$, found C 70.11, H 6.31.

4.9.2. Methyl-3-(2-methoxy-5-(3,4,5-trimethoxyphenyl)naphtalen-1-yl)acrylate (3g)

Yield: $22 \%$. Rf 0.44 (cyclohexane/EtOAc: 7/3). IR (neat) $v_{\max } / \mathrm{cm}^{-1}: 3976,3412,2939,2185,1713,1579,1503,1464$, 1414, 1278, 1171, 1153, 1126, 1063, 1008, 806. ${ }^{1} \mathrm{H}$ NMR $\left(300 \mathrm{MHz}, \mathrm{CDCl}_{3}\right) \delta 8.38(\mathrm{~d}, J=16.2 \mathrm{~Hz}, 1 \mathrm{H}), 8.20(\mathrm{~d}, J=$ $8.9 \mathrm{~Hz}, 1 \mathrm{H}), 7.96(\mathrm{~d}, J=8.9 \mathrm{~Hz}, 1 \mathrm{H}), 7.54(\mathrm{t}, J=7.2 \mathrm{~Hz}, 1 \mathrm{H}), 7.33(\mathrm{~d}, J=7.2 \mathrm{~Hz}, 1 \mathrm{H}), 7.24-7.10(\mathrm{~m}, 1 \mathrm{H}), 6.77(\mathrm{~d}, J=$ $16.2 \mathrm{~Hz}, 1 \mathrm{H}), 6.66$ (s, 2H), 3.99 (s, 3H), 3.94 (s, 3H), 3.87 (s, 9H). ${ }^{13} \mathrm{C} \mathrm{NMR}\left(75 \mathrm{MHz}, \mathrm{CDCl}_{3}\right) 168.4,156.5,153.1$ (2C), 141.1, 138.3, 137.4, 136.5, 133.3, 129.9, 127.3, 126.9, 124.9, 123.4, 123.1, 116.9, 112.7, 107.3 (2C), 77.2, 61.1, 56.3 (2C), 51.8. MS (APCI, m/z) 409.7 [M + H] $]^{+}$. Anal. Calcd for $\mathrm{C}_{24} \mathrm{H}_{24} \mathrm{O}_{6}: \mathrm{C} 70.57, \mathrm{H}$ 5.92, found C 70.21, $\mathrm{H}$ 5.68.

4.10. General procedure for catalytic hydrogenation.

A solution of suitable precursor $(50 \mathrm{mg})$ and $\mathrm{Pd} / \mathrm{C}(5 \mathrm{mg})$ in $\mathrm{MeOH}(8 \mathrm{~mL})$ was stirred under a $\mathrm{H}_{2}$ atmosphere at room temperature. After $4 \mathrm{~h}$, the medium filtered over a pad of Celite and the solvent was removed in vacuo. Purification by flash chromatography afforded compounds $\mathbf{2 a - e}$ and $\mathbf{3 h}$.

4.10.1. 6-Methoxy-1-(3,4,5-trimethoxyphenyl)-1,2,3,4-tetrahydronaphthalene (2a)

Yield: $76 \%$. Rf 0.6 (cyclohexane/EtOAc: 8/2). IR (neat) $v_{\max } / \mathrm{cm}^{-1}:$ 2931, 1589, 1500, 1462, 1417, 1328, 1232, 1124, 1038, 1007, 908, 826, 727, 647. ${ }^{1} \mathrm{H}$ NMR $\left(300 \mathrm{MHz}, \mathrm{CDCl}_{3}\right) \delta 6.80(\mathrm{~d}, J=8.3 \mathrm{~Hz}, 1 \mathrm{H}), 6.68-6.58(\mathrm{~m}, 2 \mathrm{H}), 6.31(\mathrm{~s}$, $2 \mathrm{H}), 4.01-3.94(\mathrm{~m}, 1 \mathrm{H}), 3.83(\mathrm{~s}, 3 \mathrm{H}), 3.78(\mathrm{~s}, 9 \mathrm{H}), 2.93-2.79(\mathrm{~m}, 2 \mathrm{H}), 2.19-2.07(\mathrm{~m}, 1 \mathrm{H}), 1.95-1.84(\mathrm{~m}, 2 \mathrm{H}), 1.84$ - $1.68(\mathrm{~m}, 1 \mathrm{H}) .{ }^{13} \mathrm{C} \mathrm{NMR}\left(75 \mathrm{MHz}, \mathrm{CDCl}_{3}\right)$ 157.7, 153.0 (2C), 143.5, 138.7, 136.2, 131.6, 131.2, 113.3, $112.1,105.8$

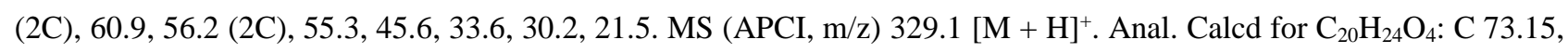
H 7.37, found C 72.89, H 7.13.

4.10.2. 2-Methoxy-5-(3,4,5-trimethoxyphenyl)-5,6,7,8-tetrahydronaphtalen-1-amine (2b)

Yield: $47 \%$. Rf 0.49 (cyclohexane/EtOAc: 6/4). IR (neat) $v_{\max } / \mathrm{cm}^{-1}: 2933,1600,1492,1458,1233,1127 .{ }^{1} \mathrm{H}$ NMR $\left(400 \mathrm{MHz}, \mathrm{CDCl}_{3}\right) \delta 6.60(\mathrm{~d}, J=8.2 \mathrm{~Hz}, 1 \mathrm{H}), 6.31(\mathrm{~d}, J=8.1 \mathrm{~Hz}, 1 \mathrm{H}), 6.32(\mathrm{~s}, 2 \mathrm{H}), 3.99(\mathrm{~m}, 1 \mathrm{H}), 3.83(\mathrm{~s}, 3 \mathrm{H}), 3.83(\mathrm{~s}$, $3 \mathrm{H}), 3.78(\mathrm{~s}, 6 \mathrm{H}), 2.59(\mathrm{~m}, 2 \mathrm{H}), 2.07(\mathrm{~m}, 1 \mathrm{H}), 1.96(\mathrm{~m}, 1 \mathrm{H}), 1.83-1.81(\mathrm{~m}, 2 \mathrm{H}), \mathrm{NH}_{2}$ not seen. The presence of an impurity complicates the NMR spectra and despite our best efforts, we were not able to obtain $\mathbf{2 b}$ with a satisfactory elemental analysis ${ }^{13} \mathrm{C}$ NMR (100 $\left.\mathrm{MHz}, \mathrm{CDCl}_{3}\right)$ 153.0 (2C), 145.1, 143.5, 136.2, 133.2, 132.3, 122.8, 119.6, 108.2, 106.0 (2C), 61.0, 56.2 (2C), 55.7, 46.0, 32.7, 24.7, 20.8. MS (APCI, m/z) $344.2[\mathrm{M}+\mathrm{H}]^{+}$.

4.10.3. 2-Methoxy-5-(3,4,5-trimethoxyphenyl)-5,6,7,7-tetrahydronaphtalen-1-ol (2c)

Yield: 50 \%. Rf 0.66 (cyclohexane/EtOAc: 7/3). IR (neat) $v_{\max } / \mathrm{cm}^{-1}: 3518,2930,2004,1589,1492,1459,1280,1234$, 1126, 907, 731, 624. ${ }^{1} \mathrm{H}$ NMR $\left(300 \mathrm{MHz}, \mathrm{CDCl}_{3}\right) \delta 6.63(\mathrm{~d}, J=8.5 \mathrm{~Hz}, 1 \mathrm{H}), 6.39(\mathrm{~d}, J=8.5 \mathrm{~Hz}, 1 \mathrm{H}), 6.32(\mathrm{~s}, 2 \mathrm{H}), 5.69$ (br s, 1H), $3.96(\mathrm{~m}, 1 \mathrm{H}), 3.86(\mathrm{~s}, 3 \mathrm{H}), 3.84(\mathrm{~s}, 3 \mathrm{H}), 3.79(\mathrm{~s}, 6 \mathrm{H}), 2.96-2.65(\mathrm{~m}, 2 \mathrm{H}), 2.17-1.73(\mathrm{~m}, 4 \mathrm{H}) .{ }^{13} \mathrm{C} \mathrm{NMR}(75$ 
$\left.\mathrm{MHz}, \mathrm{CDCl}_{3}\right)$ 153.0 (2C), 144.0, 143.4, 142.6, 133.0, 124.3, 120.9, 108.2, 105.9 (2C), 61.0, 56.2 (2C), 56.1, 45.9, 33.0, 23.3, 20.7 (one $\mathrm{C}$ missing). MS (APCI, m/z) 345.2 [M + H] $]^{+}$. Anal. Calcd for $\mathrm{C}_{20} \mathrm{H}_{24} \mathrm{O}_{5}$ : C 69.75, H 7.02, found C $69.51, \mathrm{H} 6.85$.

4.10.4. 4-(2-Methoxy-5-(3,4,5-trimethoxyphenyl)-5,6,7,8-tetrahydronaphtalen-1-yl)butan-1-ol (2d)

Yield: $34 \%$. Rf 0.31 (cyclohexane/EtOAc: 6/4). IR (neat) $v_{\max } / \mathrm{cm}^{-1}: 2004,1589,1492,1459,1280,1234,1154,1126$, 1064, 1007, 806, 730, 613. ${ }^{1} \mathrm{H}$ NMR $\left(300 \mathrm{MHz}, \mathrm{CDCl}_{3}\right) \delta 6.71(\mathrm{~d}, J=8.4 \mathrm{~Hz}, 1 \mathrm{H}), 6.63(\mathrm{~d}, J=8.4 \mathrm{~Hz}, 1 \mathrm{H}), 6.31(\mathrm{~s}$, $2 \mathrm{H}), 4.04-3.94(\mathrm{~m}, 1 \mathrm{H}), 3.84(\mathrm{~s}, 3 \mathrm{H}), 3.78(\mathrm{~s}, 9 \mathrm{H}), 3.71(\mathrm{t}, J=6.6 \mathrm{~Hz}, 1 \mathrm{H}), 2.82(\mathrm{t}, J=6.6 \mathrm{~Hz}, 2 \mathrm{H}), 2.68(\mathrm{dd}, J=12.7$

$\mathrm{Hz}, J=6.4 \mathrm{~Hz}, 2 \mathrm{H}), 2.16-1.48$ (m, 10H). ${ }^{13} \mathrm{C} \mathrm{NMR}\left(75 \mathrm{MHz}, \mathrm{CDCl}_{3}\right)$ 155.6, 153.1 (2C), 143.6, 136.5, 136.3, 131.9, 128.5, 128.4, 108.4, 106.1 (2C), 63.0, 60.9, 56.2 (2C), 55.6, 46.4, 33.0, 32.8, 26.8, 25.4, 25.4, 21.5. MS (APCI, m/z) $423.3[\mathrm{M}+\mathrm{Na}]^{+}$. Anal. Calcd for $\mathrm{C}_{24} \mathrm{H}_{32} \mathrm{O}_{5}: \mathrm{C} 71.97, \mathrm{H} 8.05$, found C 71.59, $\mathrm{H} 7.83$.

4.10.5. 1-(3,5-Dimethoxyphenyl)-6-methoxy-1,2,3,4-tetrahydronaphtalene (2e)

Yield: $72 \%$. Rf 0.25 (cyclohexane/EtOAc: 8/2). IR (neat) $v_{\max } / \mathrm{cm}^{-1}: 2939,2835,2049,2000,1595,1501,1462,1427$, 1323, 1254, 1204, 1154, 1064, 832, 697. ${ }^{1} \mathrm{H}$ NMR (300 MHz, $\left.\mathrm{CDCl}_{3}\right) \delta 6.80(\mathrm{~d}, J=8.3 \mathrm{~Hz}, 1 \mathrm{H}), 6.68-6.54(\mathrm{~m}, 2 \mathrm{H})$, $6.31(\mathrm{t}, J=2.3 \mathrm{~Hz}, 1 \mathrm{H}), 6.26(\mathrm{~d}, J=2.2 \mathrm{~Hz}, 2 \mathrm{H}), 3.99(\mathrm{t}, J=6.7 \mathrm{~Hz}, 1 \mathrm{H}), 3.78(\mathrm{~s}, 3 \mathrm{H}), 3.75(\mathrm{~s}, 6 \mathrm{H}), 2.96-2.71(\mathrm{~m}$, $2 \mathrm{H}), 2.20-2.03(\mathrm{~m}, 1 \mathrm{H}), 1.95-1.79(\mathrm{~m}, 2 \mathrm{H}), 1.79-1.65(\mathrm{~m}, 1 \mathrm{H}) .{ }^{13} \mathrm{C} \mathrm{NMR}\left(75 \mathrm{MHz}, \mathrm{CDCl}_{3}\right) 160.5(2 \mathrm{C}), 157.6$, 150.2, 138.6, 131.4, 131.3, 113.2, 112.1, 107.1 (2C), 97.6, 55.2 (2C), 55.2, 45.2, 33.1, 30.1, 21.0. MS (APCI, m/z) $299.1[\mathrm{M}+\mathrm{H}]^{+}$. Anal. Calcd for $\mathrm{C}_{19} \mathrm{H}_{22} \mathrm{O}_{3}: \mathrm{C} 76.48, \mathrm{H} 7.43$, found C 76.09, H 7.23.

4.10.6. 3-(2-Methoxy-5-(3,4,5-trimethoxyphenyl)naphtalen-1-yl)propan-1-ol (3h)

Yield: $82 \%$. Rf 0.2 (cyclohexane/EtOAc: 3/7). IR (neat) $v_{\max } / \mathrm{cm}^{-1}: 2932,2035,1582,1501,1462,1415,1332,1257$, 1126, 1040, 1007, 806, 730, 613. ${ }^{1} \mathrm{H}$ NMR $\left(300 \mathrm{MHz}, \mathrm{CDCl}_{3}\right) \delta 8.01(\mathrm{~d}, J=8.6 \mathrm{~Hz}, 1 \mathrm{H}), 7.85(\mathrm{~d}, J=9.4 \mathrm{~Hz}, 1 \mathrm{H}), 7.53$ $(\mathrm{dd}, J=8.6 \mathrm{~Hz}, J=7.0 \mathrm{~Hz}, 1 \mathrm{H}), 7.31(\mathrm{~d}, J=6.9 \mathrm{~Hz}, 1 \mathrm{H}), 7.24(\mathrm{~d}, J=10.4 \mathrm{~Hz}, 1 \mathrm{H}), 6.68(\mathrm{~s}, 2 \mathrm{H}), 3.98$ (s, $3 \mathrm{H}), 3.95$ (s, 3H), $3.87(\mathrm{~s}, 6 \mathrm{H}), 3.59(\mathrm{t}, J=5.8 \mathrm{~Hz}, 2 \mathrm{H}), 3.27(\mathrm{t}, J=7.0 \mathrm{~Hz}, 2 \mathrm{H}), 1.98(\mathrm{~m}, 2 \mathrm{H})$, OH not seen. ${ }^{13} \mathrm{C} \mathrm{NMR}(75 \mathrm{MHz}$, $\left.\mathrm{CDCl}_{3}\right)$ 154.2, 152.9 (2C), 140.9, 136.7, 133.3, 127.7, 126.2, 125.9, 124.3, 122.8, 122.5 (2C), 112.9, 107.2 (2C), 61.6, 60.9, 56.7, 56.2 (2C), 32.2, 20.6. MS (APCI, m/z) $383.8[\mathrm{M}+\mathrm{H}]^{+}$. Anal. Calcd for $\mathrm{C}_{23} \mathrm{H}_{26} \mathrm{O}_{5}: \mathrm{C} 72.23$, H 6.85, found C $72.00, \mathrm{H} 6.58$.

\subsection{Biolology}

\subsubsection{Cell Culture and Proliferation Assay.}

Cancer cell lines were obtained from the American type Culture Collection (Rockville, MD) and were cultured according to the supplier's instructions. Briefly MDA-MB-231 and H1299 cells were grown in Dulbecco minimal essential medium (DMEM) containing $4.5 \mathrm{~g} / \mathrm{L}$ glucose supplemented with $10 \%$ FCS and $1 \%$ glutamine. Human K562 leukemia and HCT116 colorectal carcinoma cells were grown in RPMI 1640 containing $10 \%$ FCS and $1 \%$ glutamine. Cell lines were maintained at $37{ }^{\circ} \mathrm{C}$ in a humidified atmosphere containing $5 \% \mathrm{CO}_{2}$. Cell viability was assessed using Promega CellTiter-Blue TM reagent according to the manufacturer's instructions. Cells were seeded in 96-well plates $(5 \times 103$ cells/well) containing $50 \mu \mathrm{L}$ growth medium. After $24 \mathrm{~h}$ of culture, the cells were supplemented with $50 \mu \mathrm{L}$ of the tested compound dissolved in DMSO (less than $0.1 \%$ in each preparation). After $72 \mathrm{~h}$ of incubation, $20 \mu \mathrm{L}$ of resazurin was added for $2 \mathrm{~h}$ before recording fluorescence $(\lambda \mathrm{ex}=560 \mathrm{~nm}, \lambda \mathrm{em}=590 \mathrm{~nm})$ using a Victor microtiter plate fluorimeter (Perkin-Elmer,USA). The $\mathrm{GI}_{50}$ corresponds to the concentration of the tested compound that caused a decrease of $50 \%$ in fluorescence of drug treated cells compared with untreated cells. Experiments were performed in triplicate. The $\mathrm{GI}_{50}$ values for all compounds were compared to the $\mathrm{GI}_{50}$ of $\mathrm{CA} 4$, isoCA-4 and isoerianin and measured the same day under the same conditions.

\subsubsection{Tubulin Binding Assay}

Sheep brain tubulin was purified according to the method of Shelanski[41] by two cycles of assembly-disassembly and then dissolved in the assembly buffer containing 0.1 M MES, $0.5 \mathrm{mM} \mathrm{MgCl}, 1 \mathrm{mM}$ EGTA, and $1 \mathrm{mM}$ GTP, pH 6.6 
(the concentration of tubulin was about $2-3 \mathrm{mg} / \mathrm{mL}$ ). Tubulin assembly was monitored by fluorescence according to reported procedure[50] using DAPI as fluorescent molecule. Assays were realized on 96-well plates prepared with Biomek NKMC and Biomek 3000 from Beckman Coulter and read at $37^{\circ} \mathrm{C}$ on Wallac Victor fluorimeter from Perkin Elmer. The $\mathrm{IC}_{50}$ value of each compound was determined as the concentration which decreased the maximum assembly rate of tubulin by $50 \%$ compared to the rate in the absence of compound. The $\mathrm{IC}_{50}$ values for all compounds were compared to the $\mathrm{IC}_{50}$ of $\mathrm{CA} 4$, isoCA-4 and isoerianin and measured the same day under the same conditions.

\section{Acknowledgments}

The CNRS (Centre National de la Recherche Scientifique) is gratefully acknowledged for financial support of this research. We thank the MRES (Ministère de la Recherche et de l'Enseignement Supérieur) for a financial fellowship to E.R. Our laboratory BioCIS-UMR 8076 is a member of the Laboratory of Excellence LERMIT supported by a grant from ANR (Agence Nationale de la Recherche, ANR-10-LABX-33). The work on tubulin was supported by a grant from ANR (ANR-09-BLAN-0071).

\section{References}

[1] A. Jordan, J. A. Hadfield, N. J. Lawrence, A. T. Mc Gown, Med. Res. Rev. 18 (1998) 259-296.

[2] T. Beckers, S. Mahboobi, Drug Future 28 (2003) 767-785.

[3] J. A. Hadfield, S. Ducki, N. Hirst, A. T. Mc Gown, Prog. Cell Cycle Res. 5, (2003) 309-325.

[4] F. Gueritte, J. Fahy, Anticancer Agents from Natural Products; G. M. Cragg, D. G. I. Kingston, D. J. Newman, Eds.; CRC Press: L. Boca Raton, (2005) 123-135.

[5] M. A. Jordan, L. Wilso, Nat. Rev. Cancer 4 (2004) 253-265.

[6] E. K. Rowinsky, R. C. Donehower, Pharmacol. Ther. 52 (1992) 35-84.

[7] R. J. Freilich, C. Balmaceda, A. D. Seidman, M. Rubin, L. M. DeAngelis, Neurology 47 (1996) 115-118.

[8] P. H. Hilkens, J. Verweij, C. J. Vecht, G. Stoter, M. J. van den Bent, Ann. Oncol. 8 (1997) 187-190.

[9] A. T. Fojo, M. Menefee, Semin. Oncol. 32 (2005) S3-S8.

[10] C. Dumontet, B. I.; Sikic, J. Clin. Oncol. 17 (1999) 1061-1070.

[11] G. R. Pettit, S. B. Singh, E. Hamel, C. M. Lin, D. S. Alberts, D. Garcia-Kendall, Experientia 45 (1989) $209-211$.

[12] G. R. Pettit, S. B. Singh, M. R. Boyd, E. Hamel, R. K. Pettit, J. M. Schmidt, F. Hogan, J. Med. Chem. 38 (1995) 1666-1672.

[13] G. R. Pettit, M. R. Rhodes, D. L. Herald, E. Hamel, J. M. Schmidt, R. K. Pettit, J. Med. Chem. 48 (2005) $4087-4099$.

[14] A. T. McGown, B. W. Fox, Cancer Chemother. Pharmacol. 26 (1990) 79-81.

[15] J.P. Liou, Y.L. Chang, F.M. Kuo, C.W. Chang, H.Y. Tseng, C.C. Wang, Y.N. Yang, J.Y. Chang, S.J. Lee, H.P. Hsieh, J. Med. Chem. 47 (2004) 4247-4257.

[16] G.M. Tozer, V.E. Prise, J. Wilson, R.J. Locke, B. Vojnovic, M.R. Stratford, M.F. Dennis, D.J. Chaplin, Cancer Res. 59 (1999) $1626-1634$.

[17] G. R. Pettit, C. Temple, V. L. Narayanan, R. Varma, M. J. Simpson, M. R. Boyd, G. A. Rener, N. Bansal, Anticancer Drug Design 10 (1995) 299-309.

[18] D. W. Siemann, D. J. Chaplin, P. A. Walicke, Expert. Opin. Investig. Drugs 18 (2009) 189-197.

[19] K. Oshumi, R. Nakagawa, Y. Fukuda, T. Hatanaka, T. Tsuji, J. Med. Chem. 41 (1998) 3022-3032.

[20] T. Hatanaka, K. Fujita, K. Oshumi, R. Nakagawa, Y. Fukuda, Y. Nihei, Y. Suga, Y. Akiyama, T. Tsuji, Bioorg. Med. Chem. Lett. 8 (1998) 3371-3374.

[21] J. W. Lippert, Bioorg. Med. Chem. 15 (2007) 605-615.

[22] K. Ohsumi, T. Hatanaka, K. Fujita, R. Nakagawa, Y. Fukuda, Y. Nihei, Y. Suga, Y. Morinaga, Y. Akiyama, T. Tsuji, Bioorg. Med. Chem. Lett. 8 (1998) 3153-3158.

[23] S. Aprile, E. Del Grosso, G.C. Tron, G. Grosa, Drug Metab. Dispos. 35 (2007) 2252-2261.

[24] C. Mousset, A. Giraud, O. Provot, A. Hamze, J. Bignon, J.-M. Liu, S. Thoret, J. Dubois, J.-D. Brion, M. Alami, Bioorg Med Chem Lett 18 (2008) 3266-3271.

[25] E. Rasolofonjatovo, O. Provot, A. Hamze, J. Bignon, S. Thoret, J.-D. Brion, M. Alami, Eur. J. Med. Chem. 45, (2010) 3617-3626.

[26] O. Provot, A. Giraud, J.-F. Peyrat, M. Alami, J.-D. Brion, Tetrahedron Lett. 46 (2005) 8547-8550.

[27] C. Mousset, O. Provot, A. Hamze, J. Bignon, J.-D. Brion, M. Alami, Tetrahedron 64 (2008) 4287-4294.

[28] N. L'Hermite, A. Giraud, O. Provot, J.-F. Peyrat, M. Alami, J.-D Brion, Tetrahedron 62 (2006), 11994-12002.

[29] A. Giraud, O. Provot, J.-F. Peyrat, M. Alami, J.-D. Brion, Tetrahedron 62 (2006) 7667-7673.

[30] S. Messaoudi, B. Tréguier, A. Hamze, O. Provot, J.-F. Peyrat, J.R. Rodrigo De Losada, J.-M. Liu, J. Bignon, J. Wdzieczak-Bakala, S. Thoret, J. Dubois, J.-D. Brion, M. Alami, J. Med. Chem. 52 (2009) 4538-4542.

[31] A. Hamze, D. Veau, O. Provot, J.-D. Brion, M. Alami, J. Org. Chem. 74 (2009) 1337-1340.

[32] E. Rasolofonjatovo, B. Tréguier, O. Provot, H. Hamze, E. Morvan, J.-D. Brion, M. Alami, Tetrahedron Lett. 52 (2011) $1036-1040$.

[33] E. Brachet, A. Hamze, J.-F. Peyrat, Jean-Daniel Brion, M. Alami, Org. Lett 12 (2011) 4042-4045.

[34] M.A. Soussi, S. Aprile, S. Messaoudi, O. Provot, E. Del Grosso, J. Bignon, J. Dubois, J.-D. Brion, G. Grosa, M. Alami, ChemMedChem 6 (2011) 1781-1788.

[35] A. Hamze, A. Giraud, S. Messaoudi, O. Provot, J.-F. Peyrat, J. Bignon, J.-M. Liu, J. Wdzieczak-Bakala, S. Thoret, J. Dubois, J.-D. Brion, M. Alami, ChemMedChem 4 (2009) 1912-1924.

[36] A. Hamze, E. Rasolofonjatovo, O. Provot, C. Mousset, D. Veau, J. Rodrigo, J. Bignon, J.-M. Liu, J. Wdzieczak-Bakala, S. Thoret, J. Dubois, J.-D. Brion, M. Alami, ChemMedChem 6 (2011) 2179-2191.

[37] S. Messaoudi, A. Hamze, O. Provot, B. Tréguier, J. Rodrigo De Losada, J. Bignon, J.-M. Liu, J. Wdzieczak-Bakala, S. Thoret, J. Dubois, J.-D. Brion, M. Alami, ChemMedChem 6 (2011) 488-497.

[38] R.B. Ravelli, B. Gigant, P.A. Curmi, I. Jourdain, S. Lachkar, A. Sobel, M. Knossow, Nature 428 (2004) $198-202$

[39] F. Lara-Otchoa, G. Espinosa-Perez, Tetrahedron Lett. 48 (2007) 7007-7010.

[40] I. Pravst, M. Zupan, S. Stavber, Tetrahedron Lett. 47 (2006) 4707-4710.

[41] B. Tréguier, A. Hamze, O. Provot, J.-D. Brion, M. Alami, Tetrahedron Lett. 50 (2009) 6549-6552.

[42] J. Barluenga, P. Morel, C. Valdés, F. Aznar, Angew. Chem. Int. Ed. 46 (2007) 5587-5590. 
[43] S. Messaoudi, J.-D. Brion, M. Alami, Adv. Synth. Catal. 352 (2010) 1677-1687.

[44] S. Messaoudi, J.-D. Brion, M. Alami, Mini-Rev. Org. Chem. 8 (2011) 448-454.

[45] K. Anderson, T. Ikawa, R. E. Tundel, S. L. Buchwald, J. Am. Chem. Soc. 128 (2006) 10694-10695.

[46] M. Alami, F. Ferri, G. Linstrumelle, Tetrahedron Lett. 34 (1993) 6403-6407.

[47] When using the NBS-bromination protocol of 6-methoxytetralone described in ref 40, beside $\mathbf{4 b}$, we have also isolated 7-bromo-6methoxytetralone $\mathbf{4} \mathbf{c}$ in a $7 \%$ yield.

[48] Giraud, O. Provot, A. Hamze, J. D. Brion, M. Alami, Tetrahedron Lett 49 (2008) 1107-1110.

[49] K.G. Pinney, V.P. Mocharla, Z. Chen, C.M. Garner, A. Ghatak, M. Hadimani, J. Kessler, J.M. Dorsey, K. Edvardsen, D.J. Chaplin, J. Prezioso, U.R. Ghatak, U.S. Patent Appl. Publ. (2004) 20040043969 A1.

[50] D.M. Barron, S.K. Chatterjee, R. Ravindra, R. Roof, E. Baloglu, D.G.I. Kingston, S. Bane, Anal. Biochem. 315 (2003) 49-56. 


\section{Legends to Figures, Schemes and Tables}

Figure 1 Representative tubulin binding agents and general structure of the synthesized analogues 1-3.

Scheme 1 Synthesis of compounds 1-3.

Scheme 2 Synthesis of compounds $1 \mathbf{k}, \mathbf{l}$.

Table 1 Cytotoxicity of compounds $\mathbf{1 - 3}$ against HCT 116 cells. $^{\text {a }}$

Table 2. Cytotoxicities of selected compounds against different human cancer cell lines and inhibition of tubulin polymerization (ITP).

Table 3. Evaluation of $\mathrm{G}_{2} / \mathrm{M}$ arrest in MDA-MB231, K562, HCT116 and H1299 cells exposed to 2c, 1e and 3d.

Figure 2. Docked pose of 2c, 1e and 3c overlayed with isoCA-4 and isoerianin in the tubulin binding site. 


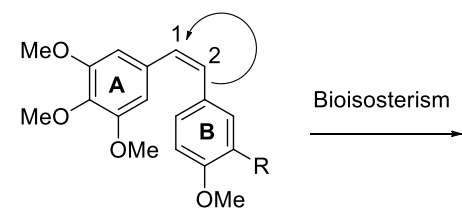

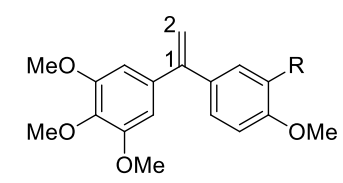

Restricted
analogues analogues

isoCA-4 $\mathrm{R}=\mathrm{OH}$

iso $\mathrm{NH}_{2} \mathrm{CA}-4 \quad \mathrm{R}=\mathrm{NH}_{2}$

isoFCA-4 $\mathrm{R}=\mathrm{F}$ $\begin{array}{ll}\text { CA-4 } & \mathrm{R}=\mathrm{OH} \\ \text { CA-4P } & \mathrm{R}=\mathrm{OPO}_{3} \mathrm{Na}_{2}\end{array}$

AVE-8062 $\mathrm{R}=\mathrm{NH}$-serine- $\mathrm{HCl}$

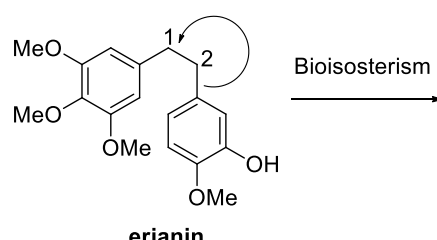

erianin

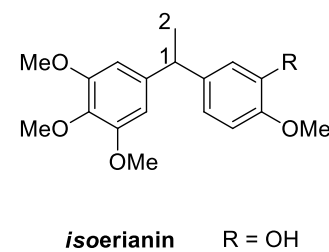

iso $\mathrm{NH}_{2}$ erianin $\mathrm{R}=\mathrm{NH}_{2}$

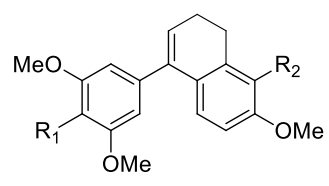

restricted isoCA-4 1

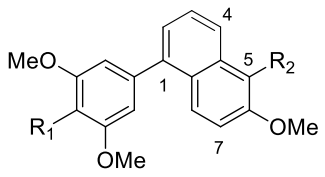

1-phenylnaphtalenes

<Figure 1>

Restricted analogues

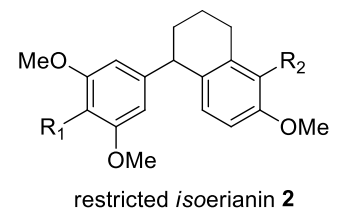




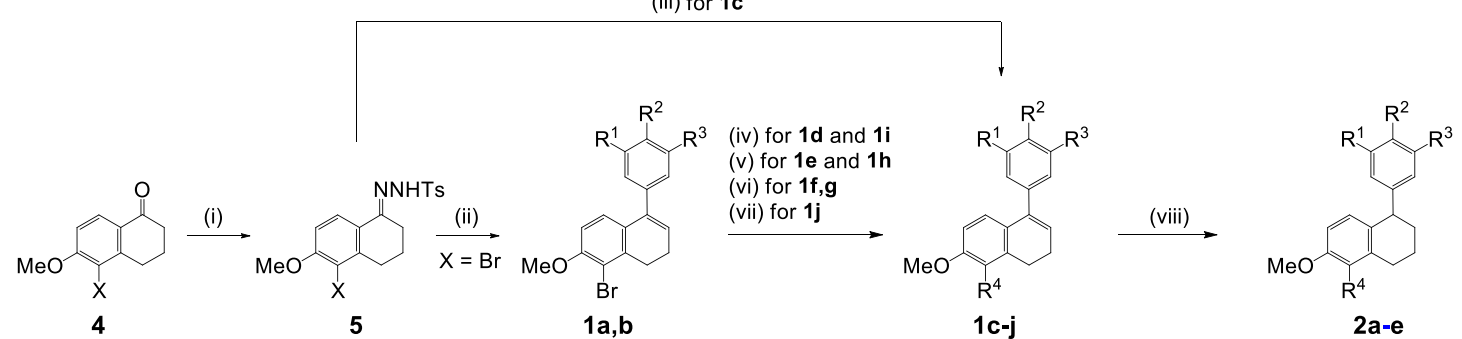

4a $X=H$

5a $X=H$

$1 \mathrm{a}, \mathrm{b}$

2a-e

4b $X=\mathrm{Br} \quad 5 b X=\mathrm{Br}$

1a $\mathrm{R}^{1}=\mathrm{R}^{2}=\mathrm{R}^{3}=\mathrm{OMe}$

1c $\mathrm{R}^{1}=\mathrm{R}^{2}=\mathrm{R}^{3}=\mathrm{OMe}, \mathrm{R}^{4}=\mathrm{H}$

2a $\mathrm{R}^{1}=\mathrm{R}^{2}=\mathrm{R}^{3}=\mathrm{OMe}, \mathrm{R}^{4}=\mathrm{H}$

1b $\mathrm{R}^{1}=\mathrm{R}^{3}=\mathrm{OMe}, \mathrm{R}^{2}=\mathrm{H}$

1d $R^{1}=R^{2}=R^{3}=O M e, R^{4}=N_{2}$

1e $\mathrm{R}^{1}=\mathrm{R}^{2}=\mathrm{R}^{3}=\mathrm{OMe}, \mathrm{R}^{4}=\mathrm{OH}$

2b $\quad R^{1}=R^{2}=R^{3}=O M e, R^{4}=\mathrm{NH}_{2}$

2c $\mathrm{R}^{1}=\mathrm{R}^{2}=\mathrm{R}^{3}=\mathrm{OMe}, \mathrm{R}^{4}=\mathrm{OH}$

1f $R^{1}=R^{2}=R^{3}=O M e, R^{4}=C=C\left(C_{2}\right)_{2} O H \quad 2 d \quad R^{1}=R^{2}=R^{3}=O M e, R^{4}=\left(C_{2}\right)_{4} \mathrm{OH}$

1g $\mathrm{R}^{1}=\mathrm{R}^{2}=\mathrm{R}^{3}=\mathrm{OMe}, \mathrm{R}^{4}=\mathrm{C} \equiv \mathrm{CCH}_{2} \mathrm{OH} \quad$ 2e $\mathrm{R}^{1}=\mathrm{R}^{3}=\mathrm{OMe}, \mathrm{R}^{2}=\mathrm{R}^{4}=\mathrm{H}$

(ix) 1h $\mathrm{R}^{1}=\mathrm{R}^{3}=\mathrm{OMe}, \mathrm{R}^{2}=\mathrm{H}, \mathrm{R}^{4}=\mathrm{OH}$

1i $\mathrm{R}^{1}=\mathrm{R}^{3}=\mathrm{OMe}, \mathrm{R}^{2}=\mathrm{H}, \mathrm{R}^{4}=\mathrm{NH}_{2}$

1j $\mathrm{R}^{1}=\mathrm{R}^{2}=\mathrm{R}^{3}=\mathrm{OMe}, \mathrm{R}^{4}=(E)-\mathrm{CH}=\mathrm{CHCO}_{2} \mathrm{Me}$

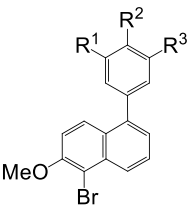

3

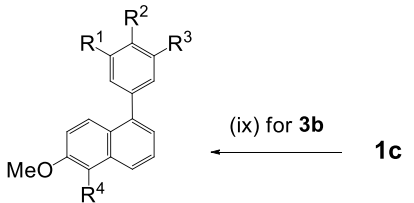

3b-h

3a $\mathrm{R}^{1}=\mathrm{R}^{2}=\mathrm{R}^{3}=\mathrm{OMe}$

3b $\mathrm{R}^{1}=\mathrm{R}^{2}=\mathrm{R}^{3}=\mathrm{OMe}, \mathrm{R}^{4}=\mathrm{H}$

3c $R^{1}=R^{2}=R^{3}=O M e, R^{4}=\mathrm{NH}_{2}$

3d $\mathrm{R}^{1}=\mathrm{R}^{2}=\mathrm{R}^{3}=\mathrm{OMe}, \mathrm{R}^{4}=\mathrm{OH}$

3e $\mathrm{R}^{1}=\mathrm{R}^{2}=\mathrm{R}^{3}=\mathrm{OMe}, \mathrm{R}^{4}=\mathrm{C} \equiv \mathrm{C}\left(\mathrm{CH}_{2}\right)_{2} \mathrm{OH}$

3f $\mathrm{R}^{1}=\mathrm{R}^{2}=\mathrm{R}^{3}=\mathrm{OMe}, \mathrm{R}^{4}=\mathrm{C} \equiv \mathrm{CCH}_{2} \mathrm{OH}$

(viii) 3g $\mathrm{R}^{1}=\mathrm{R}^{2}=\mathrm{R}^{3}=\mathrm{OMe}, \mathrm{R}^{4}=(E)-\mathrm{CH}=\mathrm{CHCO}_{2} \mathrm{Me}$

3h $\mathrm{R}^{1}=\mathrm{R}^{2}=\mathrm{R}^{3}=\mathrm{OMe}, \mathrm{R}^{4}=\left(\mathrm{CH}_{2}\right)_{3} \mathrm{OH}$

\section{$<$ Scheme 1>}



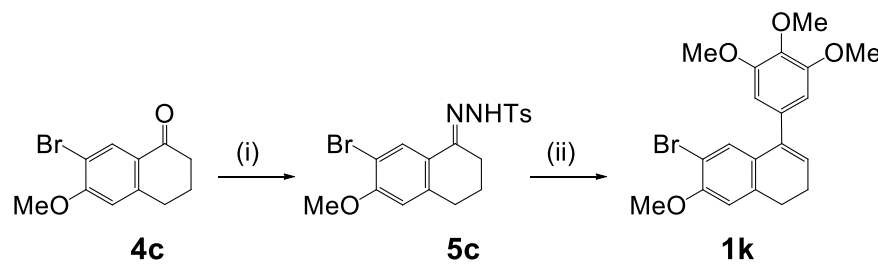

(iii)

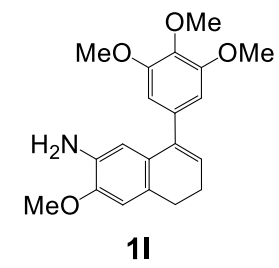

<Scheme 2> 


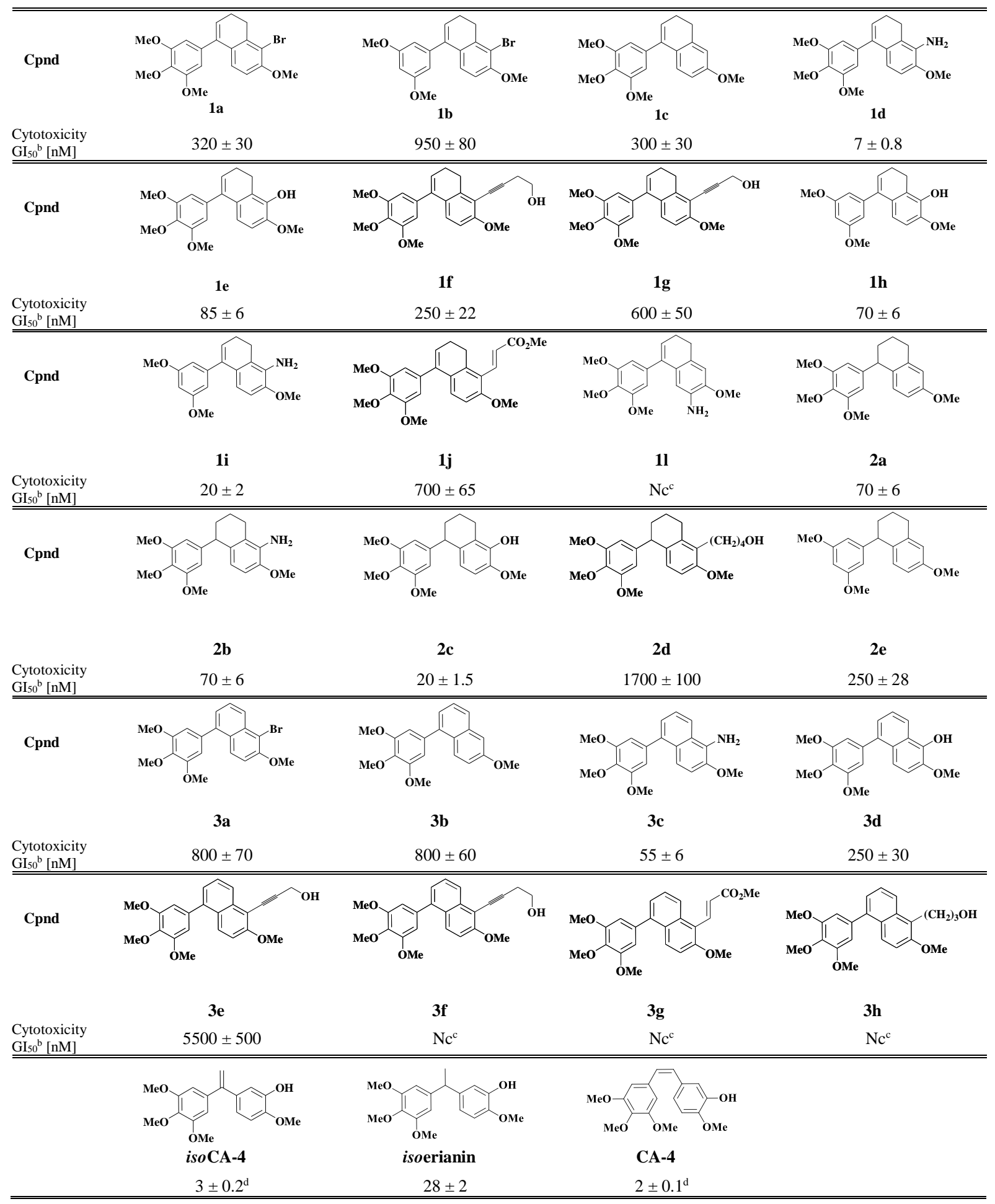

${ }^{a}$ HCT116: human colon carcinoma cells. ${ }^{b} \mathrm{GI}_{50}$ is the concentration of compound needed to reduce cell growth by $50 \%$ following 72 $\mathrm{h}$ cell treatment with the tested drug (average of three experiments). ${ }^{c} \mathrm{GI}_{50}$ value not calculated owing to the low activity of the compound. ${ }^{d}$ The $\mathrm{GI}_{50}$ values for $i s o \mathrm{CA}-4$, isoerianin and CA-4 were determined in this study.

<Table 1> 


\begin{tabular}{|c|c|c|c|c|}
\hline \multirow[b]{2}{*}{ Compound } & \multicolumn{3}{|c|}{$\mathrm{GI}_{50} \mathrm{a}[\mathrm{nM}]$} & \multirow{2}{*}{$\begin{array}{l}\text { Inhibition of tubulin } \\
\text { polymerization } \\
\mathrm{IC}_{50} \mathrm{~b}[\mu \mathrm{M}]\end{array}$} \\
\hline & $\begin{array}{l}\text { Non-small lung human carcinoma } \\
\text { (H1299) }\end{array}$ & $\begin{array}{l}\text { Human breast cancer } \\
\text { (MDA-MB231) }\end{array}$ & $\begin{array}{l}\text { Chronic mylogenous } \\
\text { leukemia (K562) }\end{array}$ & \\
\hline 1d & $30 \pm 2$ & $85 \pm 5$ & $180 \pm 14$ & $2.1 \pm 0.2$ \\
\hline $1 e$ & $32 \pm 2.5$ & $20 \pm 1.5$ & $15 \pm 0.8$ & $1.9 \pm 0.2$ \\
\hline $1 \mathrm{~h}$ & $33 \pm 2$ & $20 \pm 1$ & $20 \pm 1.5$ & $2.0 \pm 0.2$ \\
\hline $\mathbf{1 i}$ & $32 \pm 2$ & $70 \pm 6$ & $200 \pm 12$ & $3.1 \pm 0.5$ \\
\hline $2 a$ & $80 \pm 7$ & $100 \pm 7$ & $150 \pm 10$ & c \\
\hline $2 b$ & $45 \pm 3$ & $70 \pm 3$ & $110 \pm 9$ & $\mathrm{c}$ \\
\hline $2 c$ & $30 \pm 2.5$ & $30 \pm 2$ & $55 \pm 3$ & $3.0 \pm 0.3$ \\
\hline $3 c$ & $90 \pm 7$ & $60 \pm 4$ & $85 \pm 5$ & $2.0 \pm 0.3$ \\
\hline 3d & $310 \pm 25$ & $500 \pm 35$ & $380 \pm 25$ & $6.9 \pm 0.8$ \\
\hline isoCA-4 & $3 \pm 0.4$ & $4 \pm .5$ & $5 \pm 4$ & $2.2 \pm 0.2^{\mathrm{d}}$ \\
\hline isoerianin & $38 \pm 3$ & $40 \pm 5$ & $20 \pm 1.5$ & $3.2 \pm 0.3^{\mathrm{d}}$ \\
\hline CA-4 & $5 \pm 0.4$ & $3 \pm 0.3$ & $4 \pm 0.3$ & $1.0 \pm 0.2^{\mathrm{d}}$ \\
\hline
\end{tabular}

${ }^{a} \mathrm{GI}_{50}$ is the concentration of compound needed to reduce cell growth by $50 \%$ following $72 \mathrm{~h}$ cell treatment with the tested drug (average of three experiments). ${ }^{b}$ ITP, inhibition of tubulin polymerization; $\mathrm{IC}_{50}$ is the concentration of compound required to inhibit $50 \%$ of the rate of microtubule assembly (average of three experiments). ${ }^{c} \mathrm{IC}_{50}$ value not calculated owing to the low activity of the compound. ${ }^{d}$ The $\mathrm{GI}_{50}$ and $\mathrm{IC}_{50}$ values for $i s o \mathrm{CA}-4$, isoerianin and CA-4 were determined in this study.

<Table 2> 


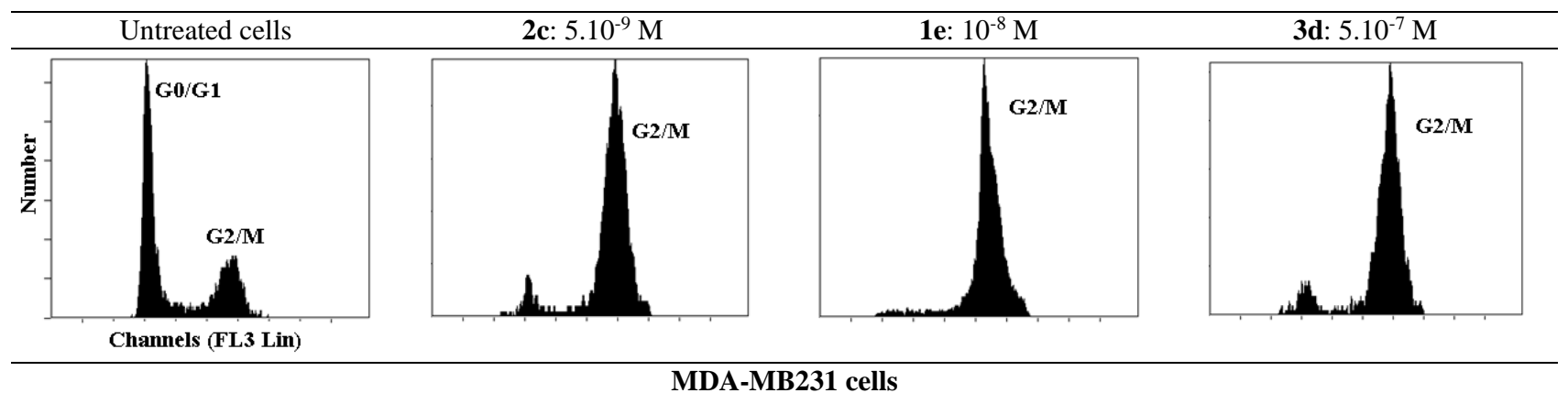
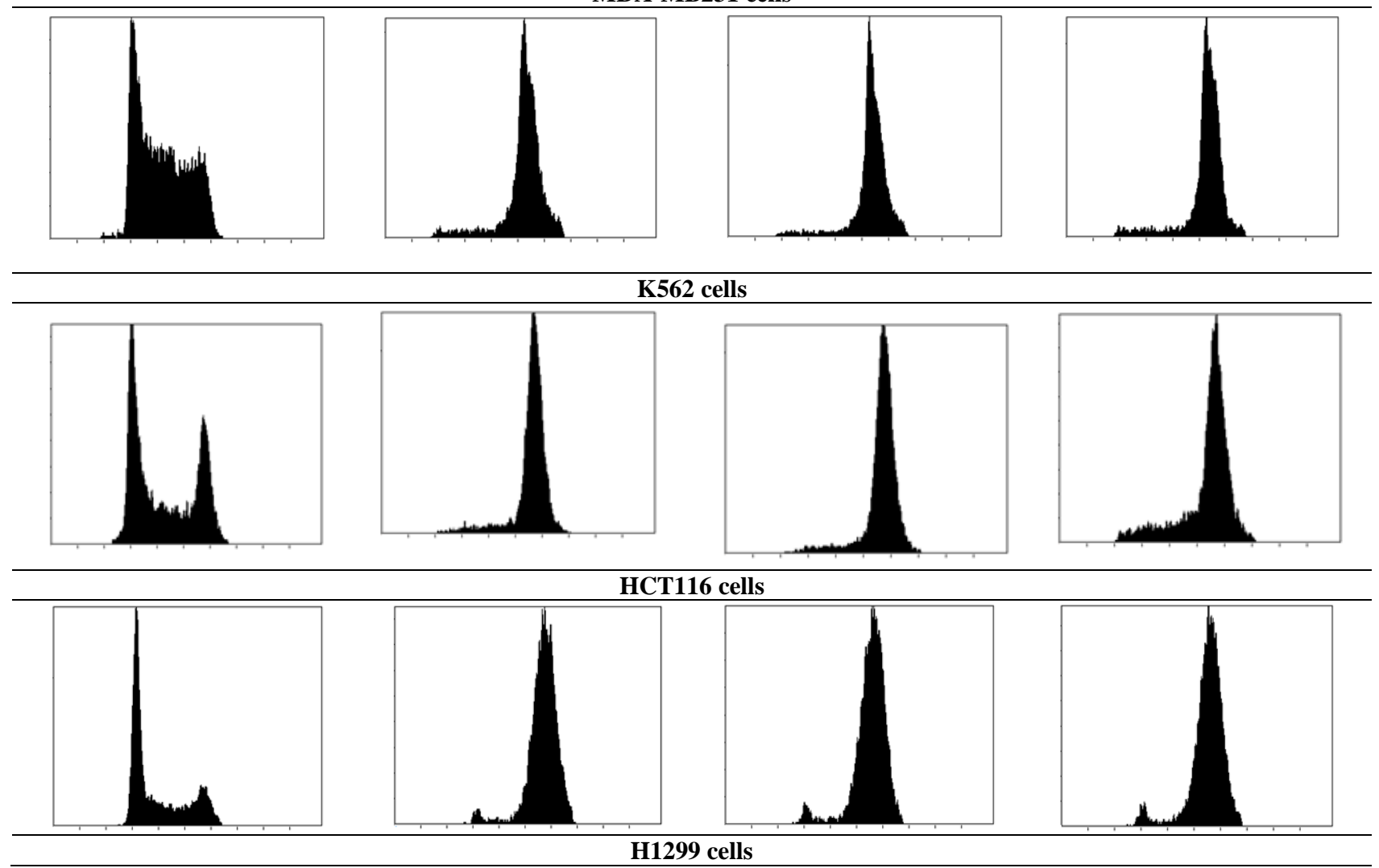

<Table 3> 


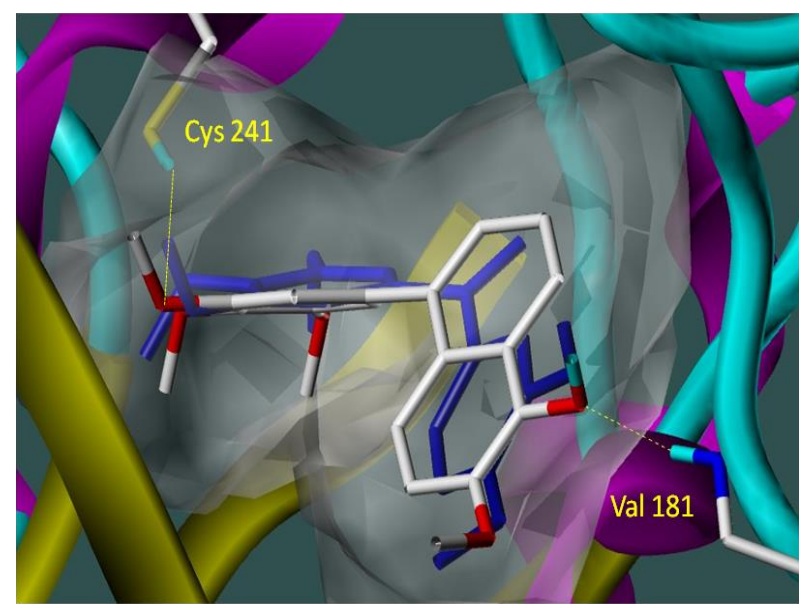

Superimposition of 2c and isoCA-4 (blue)

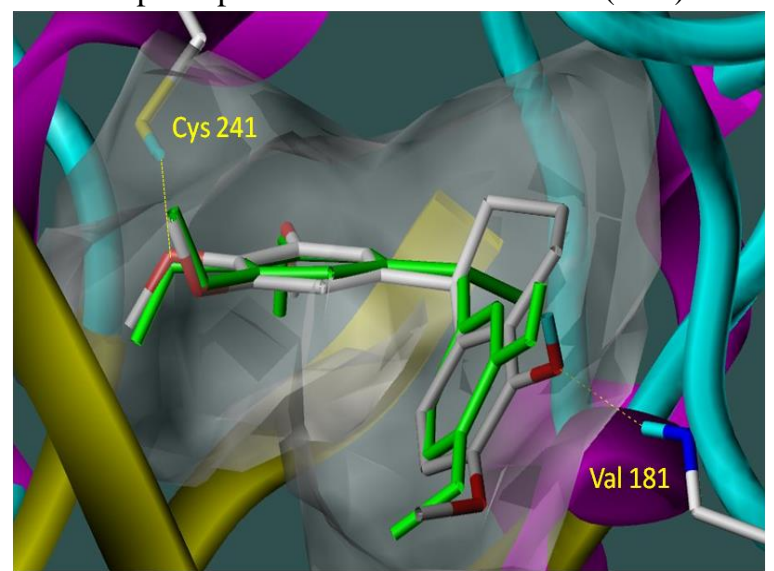

Superimposition of $\mathbf{3 d}$ and isoerianin (green)

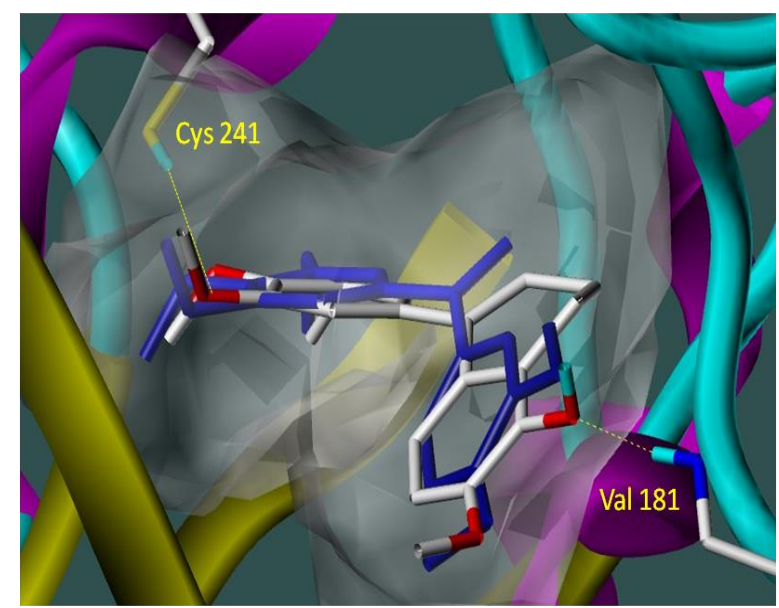

Superimposition of 1e and isoCA-4 (blue)

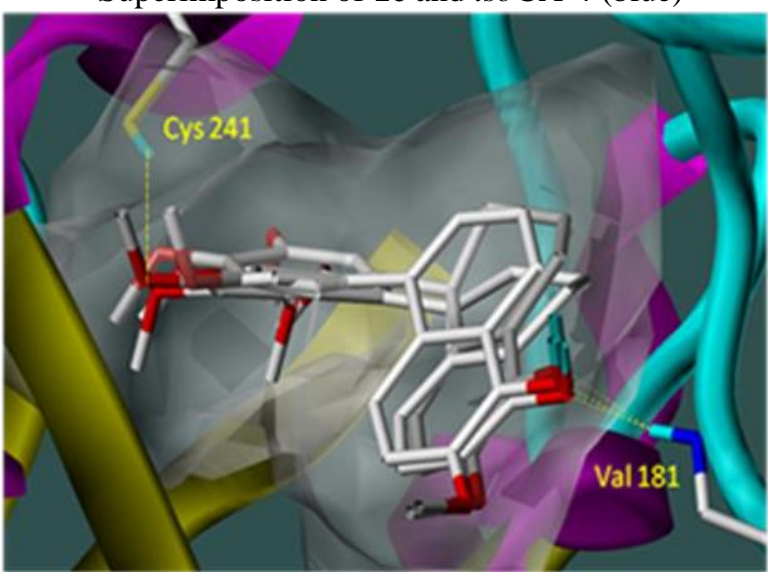

Superimposition of $\mathbf{1 e}, \mathbf{2 c}$ and $\mathbf{3 d}$

<Figure 2> 